\title{
Validación de requisitos funcionales de un Laboratorio Virtual Remoto como apoyo al blended learning
}

\section{Validation of Functional Requirements of a Virtual Remote Laboratory to Support Blended Learning}

\author{
Javier Gamo Aranda \\ Saint Louis University - Madrid Campus. España \\ gamoaranda@slu.edu \\ Jirina Novakova \\ Faculty of Education. Charles University in Prague. República Checa. \\ jirina.novakova@pedf.cuni.cz \\ Antonio MedinaRivilla \\ Facultad de Educación. UNED. España \\ amedina@edu.uned.es \\ Covadonga RodrigoSan Juan \\ Escuela Técnica Superior de Ingenieríal Informática. UNED. España. \\ covadonga@1si.uned.es
}

\begin{abstract}
Resumen
Esta investigación analiza los requisitos detectados entre estudiantes y profesores de enseñanzas científico-técnicas, sobre el diseño y funcionalidad de una futura plataforma web que implemente un Laboratorio Virtual Remoto (VRL). El VRL actualmente está en fase de diseño, y pretende servir como complemento a la enseñanza experimental en el laboratorio presencial, en las áreas de Óptica y Fotónica. A tal fin, se han diseñado dos cuestionarios (para profesores y estudiantes, respectivamente), con el fin de recabar las necesidades y expectativas de ambos colectivos, en el uso y contenidos de la plataforma virtual. Los cuestionarios se han editado en inglés y español, su contenido ha sido validado previamente por expertos nacionales e internacionales en ciencias, ingeniería y educación, y se han distribuido en línea entre estudiantes y profesores de universidades españolas y extranjeras. El trabajo detalla la estructura de los cuestionarios, la valoración de los expertos sobre su contenido, el análisis de fiabilidad realizado, los resultados obtenidos en la cumplimentación por profesores y estudiantes, y la discusión de dichos resultados, realizada con la ayuda de un grupo de expertos.
\end{abstract}

\section{Palabras claves}

Enseñanza por ordenador, Laboratorio Virtual Remoto, Óptica y Fotónica, Cuestionarios de requisitos.

\footnotetext{
Abstract

This research analyzes the requirements detected among students and teachers of scientifictechnical education, on the design and functionality of a future web platform implementing a Virtual Remote Laboratory (VRL). The VRL is currently in the design phase, and is intended to supplement the experimental classroom teaching on Optics and Photonics. To this end, we have designed two surveys (for teachers and students, respectively), in order to gather their needs and expectations on the use and contents of the virtual platform. Surveys have been published in English and Spanish, their contents were validated by experts worldwide in science, engineering and education, and distributed online between students and teachers of Spanish and foreign universities. This paper describes the detailed structure of the surveys, the assessment by experts on the content thereof, the reliability analysis
} 
performed, the results of the completion by teachers and students, and the discussion thereof, conducted jointly with the help of a group of experts.

Keywords: Computer-aided teaching, Virtual Remote Laboratory, Optics and Photonics, Requirement surveys

\section{Introducción}

El presente trabajo indaga sobre los requisitos funcionales y de diseño de una plataforma VRL, en el ámbito de la Óptica y la Fotónica; tras esta sección de introducción, la sección "Objetivos" describe las características concretas, previamente identificadas, de la plataforma VRL a diseñar. A continuación, la sección "Situación de partida" analiza algunas de las experiencias previas más notables en VRLs, encontradas en la literatura. La sección “"

Diseño e Implementación" describe la estructura de los cuestionarios elaborados para profesores y estudiantes, que recaban las necesidades y requisitos de ambos colectivos, respecto al uso de plataformas digitales de enseñanza, contenidos y herramientas a incluir en el futuro VRL, y preferencias respecto a los modelos de laboratorio virtual o remoto. El análisis de los datos recabados se realiza en la sección "

Resultados”, mientras que la sección “

Conclusiones y líneas futuras" resume los aspectos esenciales encontrados en esta investigación, y describe los siguientes pasos previstos para continuar el desarrollo.

A nadie sorprende hoy día la afirmación de que el desarrollo de las Tecnologías de la Información y las Comunicaciones (TIC), y más concretamente, la popularización de internet, han revolucionado todas las facetas de actividad del ser humano. Cualquier aspecto de la vida (artes, ciencias, negocios, relaciones personales, etc.) se ha visto agitado por este nuevo paradigma de la comunicación global.

Sin duda, en el ámbito educativo, las TIC están produciendo una auténtica revolución. El modelo tradicional de enseñanza, donde el profesor poseía el saber, y lo transmitía unidireccionalmente a los estudiantes, está ya caduco. Hoy día, cualquier estudiante, sea del nivel educativo que sea, puede acceder a una ingente cantidad de recursos formativos, que abarcan absolutamente todas las ramas del saber.

El papel del profesorado debe adaptarse a este nuevo entorno, pasando de ser poseedor y transmisor del conocimiento, a ser facilitador del proceso de enseñanza-aprendizaje. El estudiante pasa a estar ahora en el centro del proceso de enseñanza-aprendizaje, y tiene todo el universo del conocimiento a su alcance.

Los modelos de enseñanza virtual (e-learning, b-learning, y sus distintas variantes) están siendo utilizados por empresas y centros de todos los niveles educativos, para la formación en cualquier disciplina. Mediante el uso de las TIC, las instituciones pueden proporcionar formación a trabajadores y estudiantes de forma generalizada, con evidentes ventajas en ahorro de costes, flexibilización de horarios para el seguimiento de los cursos, cooperación entre entidades de todo el mundo, etc.

En el ámbito universitario, la declaración de Bolonia respecto al Espacio Europeo de

Validación de requisitos funcionales de un Laboratorio Virtual Remoto como apoyo al blended learning. J. Gamo et al. 
Enseñanza Superior (EEES) refuerza los procesos de aprendizaje-enseñanza basados en competencias (The Bologna Process, 2014). La competencia digital es uno de los aspectos clave para acceder hoy día al mercado laboral. Por otra parte, las TIC están cambiando la forma en que la educación se está llevando a cabo (Alberca, Nogueras, Reina, \& Rodríguez, 2010). Muchos de los contenidos de las asignaturas se imparten a través de plataformas de aprendizaje on-line, permitiendo al estudiante complementar la tradicional enseñanza en clase presencial, con el aprendizaje autónomo y colaborativo a la vez, desde casa.

En este contexto, el auge de las TIC está empujando a las universidades presenciales a actualizarse, para no perder aquellos estudiantes que ven en las instituciones on-line, una forma de compaginar el desarrollo formativo con el desempeño de una carrera profesional, a la vez que ofrecen una mejor conciliación con la vida familiar y personal.

Los estudios universitarios de carácter científico-técnico son buenos candidatos para implementar innovaciones educativas relacionadas con las TIC. Los estudiantes de estas disciplinas están habituados al uso de las TIC, por lo que pueden adoptar rápidamente nuevas tecnologías para el aprendizaje. Además, muchas de las asignaturas científicotécnicas requieren la realización de prácticas de laboratorio, cuya implementación a través de plataformas virtuales de enseñanza constituye un sugerente reto, y a la vez una gran oportunidad, para el mundo académico.

En este panorama, los últimos años han visto un gran auge en la investigación y desarrollo de Laboratorios Virtuales Remotos (Virtual Remote Labs - VRLs), tanto en la enseñanza secundaria (Dziabenko \& García-Zubía, 2013), como en la universitaria (García-Zubía \& Alves, 2011).

Podemos definir un VRL como una plataforma donde se realizan experimentos científico-técnicos, mediante el uso de las TIC (Gamo, 2013). Dentro de un VRL, se suele distinguir entre:

- Laboratorio Virtual, que incluye la simulación por ordenador de fenómenos y procesos (físicos, químicos, biológicos, etc.), utilizando algoritmos que implementan las leyes que describen dichos fenómenos (Mitchell-Waldrop, 2013).

- Laboratorio Remoto, en los que se produce una interacción a distancia con equipos e instrumentos, que están físicamente localizados en una ubicación distinta desde la que se controla el experimento (Chaos, Chacón, Lopez-Orozco, \& Dormido, 2013).

En muchos casos, los conceptos de Laboratorio Virtual y Remoto aparecen simultáneamente en la misma plataforma de experimentación.

Las ventajas de los VRL en enseñanzas científico-técnicas son múltiples, destacando (Ros, 2012):

- Acceso al VRL desde múltiples localizaciones geográficas (por ejemplo, estudiantes de distintas ciudades, países, etc.).

Validación de requisitos funcionales de un Laboratorio Virtual Remoto como apoyo al blended learning. J. Gamo et al. 
- Compartición eficiente de recursos (por ejemplo, entre distintos centros de enseñanza, o distintos campus de la misma universidad), lo que redunda en economías de escala.

- Mejora de la calidad, a través de la especialización (por ejemplo, cada centro puede centrarse en desarrollar de forma óptima una/varias prácticas, en lugar de acometer el desarrollo de todas las que correspondan a una misma asignatura).

- $\quad$ Seguridad y prevención (por ejemplo, los experimentos pueden realizarse sin peligro para los estudiantes, en caso de fallo).

\section{Objetivos}

Este trabajo trata de investigar sobre los requisitos y funcionalidad que, a juicio de estudiantes y profesores, debe tener una plataforma de enseñanza digital, orientada a la experimentación virtual, denominada OPTILAB. Podemos definir OPTILAB como una plataforma VRL, a través de la cual los estudiantes de carreras universitarias científicotécnicas podrán simular las prácticas relacionadas con la Óptica y la Fotónica, antes de enfrentarse a la realización física de los experimentos en un laboratorio presencial.

Todo VRL precisa de una serie de elementos técnicos para su implementación. Las premisas de partida para la plataforma OPTILAB, son las siguientes:

- Sistema abierto: OPTILAB pretende ser un sistema de experimentación abierto, esto es, que puedan acceder estudiantes de cualquier lugar geográfico, únicamente disponiendo de una conexión a internet, y utilizando un navegador convenientemente actualizado. Inicialmente, se tiene previsto que el proceso de registro en la plataforma sea utilizado únicamente para contabilizar el número de accesos y la localización geográfica de los usuarios, de forma que sirva para identificar tendencias y hábitos de uso (horarios de conexión, tiempos de utilización de la plataforma, contenidos y herramientas más demandados, etc.).

Con el tiempo, si se observa una utilización masiva del sistema, que pudiera poner en compromiso la usabilidad del portal, se podrán establecerán mecanismos para limitar el uso de la plataforma (por ejemplo, tiempo límite de sesión y/o número de intentos de acceso a determinados contenidos, etc.).

- Sistema multiplataforma: el concepto de sistema abierto afecta también al aspecto tecnológico; la plataforma OPTILAB deberá ser compatible con los distintos sistemas operativos y navegadores más populares del mercado. Especial atención deberá prestarse a la usabilidad del sistema, debiendo garantizarse que el diseño de la plataforma OPTILAB cumpla con los criterios de facilidad de uso y utilidad percibidos.

- Sistemas colaborativo y autónomo: una de las máximas que guiará el proceso de construcción de la plataforma OPTILAB será el aprendizaje colaborativo. Cada vez más, el modelo colaborativo se está imponiendo en todos los ámbitos de la sociedad actual: redes sociales, innovación abierta, Curos En línea Abiertos y Masivos (MOOC). OPTILAB no será ajeno a esta tendencia, e incluirá, ya desde la fase de

Validación de requisitos funcionales de un Laboratorio Virtual Remoto como apoyo al blended learning. 
diseño, herramientas encaminadas a promover e incentivar la colaboración en el proceso de enseñanza-aprendizaje. No obstante, los autores son conscientes de que el aprendizaje de cualquier disciplina requiere siempre un componente de trabajo autónomo importante, por lo que OPTILAB deberá incluir también herramientas que faciliten este tipo de aprendizaje.

Para poder desarrollar la plataforma OPTILAB con las premisas anteriores, es necesario llevar a cabo un estudio que recoja las necesidades y expectativas de los usuarios finales, de forma que se contrasten las ideas que tiene el diseñador de la plataforma, con lo que esperan realmente dichos usuarios. De otra forma, se puede realizar el mejor desarrollo técnico, pero éste servirá de poco, si al final no resulta útil para los usuarios a quienes está destinado.

En este sentido, se entiende por usuarios finales tanto a los estudiantes (últimos destinatarios de todo proceso de enseñanza-aprendizaje), como a los profesores que utilicen la plataforma VRL, siempre entendiendo que dicha plataforma servirá como un complemento a la enseñanza presencial desarrollada en el aula de laboratorio.

Por tanto, el objetivo concreto de la investigación que se presenta en este artículo puede formularse como sigue: comprobar las expectativas y necesidades de los colectivos de profesores y estudiantes de titulaciones de ciencias e ingenierías respecto a los VRLs.

Para acometer la resolución de este problema, se han diseñado sendos cuestionarios de requisitos, uno para profesores (Gamo J. , Survey on Virtual Remote Labs (teachers), 2014), otro para estudiantes (Gamo J. , Survey on Virtual Remote Labs (students), 2014). Como es sabido, los cuestionarios son una herramienta altamente utilizada en investigación, especialmente en el ámbito de las ciencias sociales y educativas. El cuestionario estructurado representa el principal instrumento de recogida de datos, teniendo en cuenta el alto volumen de los mismos, y la previsible dispersión de la muestra (Frey \& Botan, 2000).

El nuevo paradigma suscitado recientemente en la enseñanza es el Curso En Línea, Abierto y Masivo (MOOC). Se trata de cursos, por lo general de corta duración, normalmente impartidos por universidades de prestigio, que pretende introducir al estudiante en alguna disciplina, como complemento a la enseñanza presencial. OPTILAB pretende compartir con los MOOC algunas de sus características, especialmente la universalidad en el acceso, el aprendizaje colaborativo, y el uso de recursos multimedia.

\section{Situación de partida}

Como paso previo al diseño de la plataforma OPTILAB, se han analizado las siguientes plataformas VRL de experimentación en ciencias e ingeniería:

\section{1 iLab - MIT}

El Massachusetts Institute of Technology (MIT) pone a disposición de la comunidad global el portal iLab. Con esta iniciativa de laboratorios a través de internet, el MIT pretende ampliar considerablemente la gama de experimentos en los que los estudiantes están expuestos durante su ciclo educativo (Hardesty, 2010). Actualmente, cualquier

Validación de requisitos funcionales de un Laboratorio Virtual Remoto como apoyo al blended learning. J. Gamo et al. 
internauta puede solicitar acceso a iLab, para realizar experimentos virtuales mediante un navegador que tenga Java instalado. De momento, iLab no incluye ningún laboratorio en Óptica/Fotónica.

\subsection{UNEDLabs}

UNEDLabs aglutina una red de laboratorios virtuales, remotos y colaborativos de la Universidad Nacional de Educación a Distancia (UNED, 2013). En UNEDLabs, estudiantes de distintas carreras de la UNED pueden realizar sus prácticas experimentales, tanto reales como simuladas, mediante un entorno web que permite manejar a distancia los recursos experimentales que, físicamente, se encuentran ubicados en un laboratorio real de la UNED. Actualmente, en UNEDLabs se pueden realizar experimentos de Automática, Matemáticas, Control de Procesos Avanzados, Técnicas Experimentales de Física, etc., si bien de momento, no incluye prácticas en Óptica/Fotónica.

\subsection{Javaoptics}

El proyecto Javaoptics (JOptics) es una iniciativa del Grupo de Innovación Docente en Óptica Física y Fotónica de la Universidad de Barcelona, cuyo objetivo es fomentar el aprendizaje de la Óptica a través de Internet para estudiantes universitarios (Carnicer, 2014). Además, una parte de los materiales desarrollados pueden ser utilizados por estudiantes y profesores de ESO y bachillerato, para ilustrar y ampliar conceptos de Física, a ese nivel educativo.

Actualmente, JOptics permite realizar experimentación virtual sobre 12 fenómenos ópticos. Las simulaciones pueden ejecutarse directamente como applets en el navegador, o bien descargarse en el ordenador para ejecutarse posteriormente, sin necesidad de conexión a internet. JOptics ha sido galardonado con el premio MERLOT Classics Awards 2010 dentro del apartado de Física (MERLOT, 2010). A pesar del excelente material, JOptics no incluye herramientas colaborativa (foros, por ejemplo), ni permite una evaluación on-line del aprendizaje de los contenidos.

\section{Diseño e Implementación}

Los cuestionarios de requisitos se han editado en inglés y español, y fueron distribuidos entre estudiantes y profesores nacionales e internacionales. Para facilitar su cumplimentación, los cuestionarios han sido editados directamente en la web, mediante la herramienta Qualtrics (Snow, 2014), distribuyéndose la URL de acceso, mediante correo electrónico, a profesores y estudiantes de universidades españolas y extranjeras.

La Figura 1 muestra el aspecto del cuestionario de requisitos para estudiantes. El cuestionario de requisitos para profesores tiene un aspecto similar.

Validación de requisitos funcionales de un Laboratorio Virtual Remoto como apoyo al blended learning. 


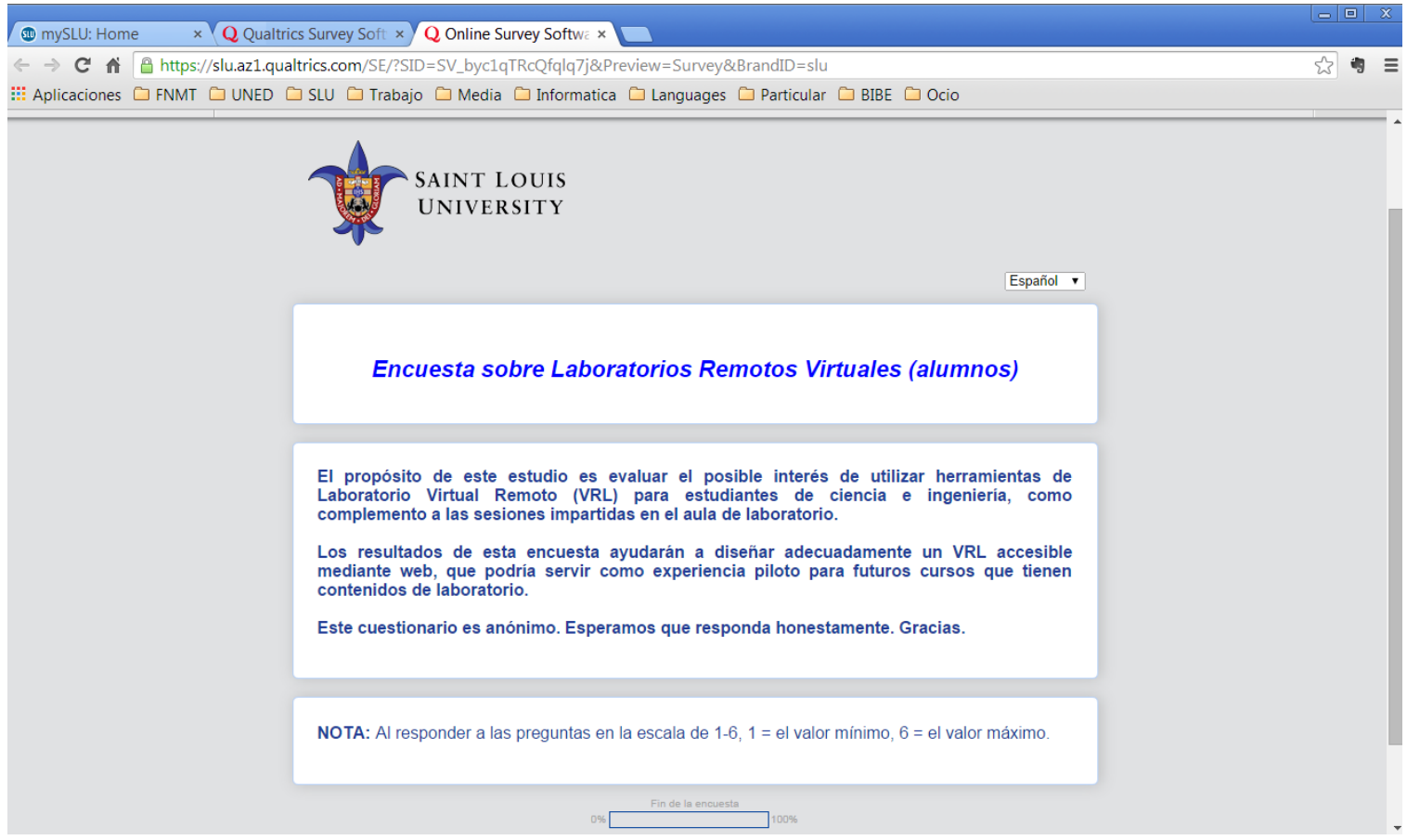

Figura 1 Cuestionario para estudiantes, en el modo cumplimentación como aparece a los encuestados

\subsection{Validez de contenido}

Para determinar la validez de contenido de los cuestionarios de requisitos de estudiantes y profesores, se ha recurrido a la opinión de expertos en el objeto de la investigación. La Tabla 1 resume el número, procedencia y área de conocimiento de los expertos participantes. La elección de expertos de distintas áreas obedece al hecho de intentar recoger la doble visión perseguida en este trabajo (didáctico-pedagógica por una parte, y científico-técnica por otra).

Tabla 1. Grupo de expertos participantes en el diseño de los cuestionarios de requisitos de estudiantes y profesores

\begin{tabular}{|l|l|l|}
\hline Procedencia expertos & Área de conocimiento & $\mathbf{N}^{\mathbf{o}}$ expertos \\
\hline \multirow{3}{*}{ Españoles } & Ciencias e Ingeniería & 7 \\
\cline { 2 - 3 } & Educación & 3 \\
\hline \multirow{3}{*}{ Extranjeros } & Ciencias e Ingeniería & 7 \\
\cline { 2 - 3 } & Educación & 2 \\
\hline
\end{tabular}

El trabajo de revisión de los contenidos de los cuestionarios de requisitos por parte de los expertos, perseguía un doble objetivo:

- Por una parte, evaluar la pertinencia de las distintas preguntas sobre el objeto de investigación, sugiriendo las modificaciones correspondientes. 
- Por otra parte, depurar aquellos apartados del cuestionario que pudiesen dar lugar a confusión, a la hora de ser respondidos por los encuestados.

A todos estos expertos, se les remitió una versión preliminar de ambos cuestionarios; una vez recabadas sus opiniones, se construyó la versión definitiva de los mismos. Ambos cuestionarios, tienen una estructura común, formada por un bloque de introducción, y 3 bloques de preguntas. A continuación, se describen en detalle cada uno de los apartados de ambos cuestionarios, con las opciones de respuestas en cada caso, así como los comentarios más relevantes aportados por los expertos consultados.

\subsection{Bloque de introducción}

El propósito de esta sección es presentar el objetivo de la encuesta. Además de mostrar el título en el encabezado, "Encuesta sobre Laboratorios Remotos Virtuales" (seguido del sustantivo (estudiantes) o (profesores), según el colectivo a quien se dirija el cuestionario), se informa al encuestado de que los resultados de esta encuesta ayudarán a diseñar adecuadamente un VRL basado en la web, que podría servir como experiencia piloto para futuros cursos que tienen contenidos de laboratorio.

Muchos de los expertos consultados coincidieron en que, la preservación de la confidencialidad de los datos personales de los encuestados, es altamente recomendable, como una manera de alentar a la población contactada a participar en la encuesta. Por lo tanto, el carácter anónimo de las encuestas se menciona explícitamente en esta sección introductoria.

Asimismo, en esta sección de introducción, se indica al encuestado que, al responder a las preguntas con escala de valoración de 1 a 6 , el valor 1 corresponde al valor mínimo, mientras que 6 hace referencia al valor máximo. Evidentemente, se está utilizando una escala Likert de 6 puntos ( 1 - 6), donde los valores de dicha escala vienen representados gráficamente por estrellas (******) en los cuestionarios on-line (Likert, 1932).

$\mathrm{Al}$ respecto de la escala de Likert, existen diversas opiniones sobre el número de niveles a utilizar en la misma (Edmondson, 2005). Normalmente, el formato más popular consiste en una escala de Likert de 5 puntos, como sigue:

1. Muy satisfecho

2. Satisfecho

3. Ni satisfecho ni insatisfecho

4. Insatisfecho

5. Muy insatisfecho

Otra versión de la escala que se puede encontrar, utiliza 6 niveles, a saber:

1. Extremadamente satisfecho

2. Muy satisfecho

3. Algo satisfecho

4. Algo insatisfecho

5. Muy insatisfecho

6. Extremadamente insatisfecho

Validación de requisitos funcionales de un Laboratorio Virtual Remoto como apoyo al blended learning. 
Existen razones, a favor y en contra, de utilizar un número par o impar de niveles de cuantificación (Infosurv, Inc., 2011). En nuestro caso, somos partidarios de adoptar una escala de 6 puntos en las preguntas de valoración. Las razones son las siguientes:

- Estamos en desacuerdo con proporcionar al encuestado una opción de respuesta neutra o ambivalente (punto central de la escala). Preferimos ofrecer un número par de calificaciones en la escala, para así disponer de encuestados "comprometidos" hacia algunos de los extremos (positivo o negativo) de la escala.

- Las respuestas neutras son raras de todos modos, porque en la mayoría de los casos, sólo aquellos encuestados que tuvieron una experiencia/opinión positiva o negativa querrán participar en un estudio de investigación.

- Mediante una escala par, los resultados pueden analizarse por segmentos (1 - 2, 3 4, 5 - 6), lo cual puede servir de ayuda en el análisis de las respuestas.

Respecto a la codificación de variables, se ha seguido la siguiente convención de nomenclatura:

\section{$[\mathrm{E} / \mathrm{P}] .[\mathrm{VE} / \mathrm{VP} / \mathrm{VS}][\mathrm{N} . \mathrm{M}]$}

donde:

- $\quad[\mathrm{E} / \mathrm{P}]$ se refiere a que el cuestionario está dirigido a estudiantes $(\mathrm{E})$ o profesores $(\mathrm{P})$.

- $\quad[V E / V P / V S]$ hace referencia a si se trata de una variable de entrada (VE), de proceso (VP), o de salida (VS), como se explica a continuación.

- $\quad[N]$ denota el subgrupo dentro de cada clase de variable, como se describe más adelante.

- $[\mathrm{M}]$ es el número de orden de la variable de tipo $\mathrm{N}$.

Las variables se han clasificado en 3 categorías, a saber:

- Variables de Entrada (VE): también llamadas variables categóricas, son aquellas que dependen de su propia naturaleza, y no son alterables. Normalmente, sirven para identificar de forma unívoca las características de la población encuestada. Las variables de entrada incluyen:

○ Datos personales

- Datos de disponibilidad de TIC

- Variables de Proceso (VP): son las que recogen la parte esencial del trabajo de investigación; pretenden recabar la opinión de la población encuestada sobre los aspectos más relevantes del estudio. En nuestro caso, las variables de proceso contienen:

- Datos académicos generales

- Datos sobre enseñanza presencial con apoyo virtual

- Datos sobre enseñanza totalmente virtual

- Datos de utilización de TIC

○ Datos sobre aprendizaje autónomo

Validación de requisitos funcionales de un Laboratorio Virtual Remoto como apoyo al blended learning. J. Gamo et al. 
- Datos sobre aprendizaje colaborativo

- Variables de Salida (VS): también llamadas variables de producto, son las que condensan el resultado final del trabajo de investigación. En ellas, se pretende constatar las tesis defendidas inicialmente, o por el contrario, reconducir la investigación posterior hacia los requisitos y necesidades detectadas en dichas variables. Las variables de salida se agrupan como sigue:

- Datos sobre satisfacción de la enseñanza presencial con apoyo virtual

- Datos sobre satisfacción de la enseñanza totalmente virtual

- Confluencia de los modelos de enseñanza presencial y virtual

- Datos sobre contenidos de la plataforma VRL

- Datos sobre herramientas de aprendizaje autónomo del VRL

- Datos sobre herramientas colaborativas del VRL

- Otros datos no contemplados inicialmente

\subsection{Preguntas sobre población encuestada (bloque 1)}

El objetivo de este bloque, es determinar las variables de identificación (género, edad, universidad, etc.) de las dos poblaciones encuestadas en cada caso (profesores y estudiantes). El propósito es poder establecer inter-comparaciones entre variables, sobre los resultados recogidos en los siguientes bloques. De esta forma, se podrán estudiar tendencias en las respuestas obtenidas, en función de dichas variables de identificación.

La Tabla 2 resume las variables de identificación, así como las respuestas esperadas en cada caso. Por simplicidad, la tabla sintetiza ambas encuestas, donde se agrupan las respuestas comunes, y se señalan las opciones particulares, cuando proceda. También se ha eliminado el indicativo [E/P] correspondiente a estudiantes o profesores, para aligerar el contenido de la tabla-resumen.

Tabla 2. Preguntas sobre población encuestada en los dos cuestionarios de requisitos

\begin{tabular}{|c|c|c|c|}
\hline \# & Variable & Estudiantes & Profesores \\
\hline $\begin{array}{l}\text { VE1. } \\
1\end{array}$ & Edad & $18 \ldots>30$ & $20-30 \ldots>60$ \\
\hline $\begin{array}{l}\text { VE1. } \\
2\end{array}$ & Género & \multicolumn{2}{|c|}{ Hombre / Mujer / Prefiero no especificar } \\
\hline VP1.1 & Universidad & \multicolumn{2}{|l|}{ (listado de universidades) } \\
\hline VP1.2 & Especialidad $^{1}$ & \multicolumn{2}{|l|}{ (listado de especialidades) } \\
\hline VP1.3 & Curso $^{2}$ & \multicolumn{2}{|l|}{$1-5,>5$} \\
\hline $\begin{array}{l}\text { VE1. } \\
3\end{array}$ & ¿Trabaja? & Sí / No & No aplica \\
\hline VP1.4 & $\begin{array}{l}\text { Estudios } \\
\text { previos }\end{array}$ & $\begin{array}{l}\text { Primarios / Bachiller / COU / FP } 2^{\circ} \text { Ciclo / } \\
\text { Graduado / Diplomado / Ing. Técnico / } \\
\text { Máster / Licenciado / Ing. Superior / DEA / } \\
\text { Doctor }\end{array}$ & No aplica \\
\hline $\begin{array}{l}\text { VE1. } \\
4\end{array}$ & $\begin{array}{l}\text { Ocupación } \\
\text { principal }\end{array}$ & $\begin{array}{l}\text { Estudiante / Estudiante y busco empleo / } \\
\text { Estudiante y tengo trabajo fijo / Estudiante } \\
\text { jubilado }\end{array}$ & $\begin{array}{l}\text { Profesor tiempo } \\
\text { completo / } \\
\text { Profesor tiempo } \\
\end{array}$ \\
\hline
\end{tabular}

Validación de requisitos funcionales de un Laboratorio Virtual Remoto como apoyo al blended learning. J. Gamo et al. 
\begin{tabular}{|l|l|l|}
\hline & & parcial \\
\hline
\end{tabular} especialidad(es) en que imparte docencia

${ }^{2}$ Estudiantes: curso más alto en que se encuentra matriculado; Profesores: cursos en que imparte docencia

Los expertos indicaron que, en algunos países (como Estados Unidos), algunas personas prefieren no especificar el género, por las posibles implicaciones que esto pudiera conllevar, a la hora de interpretar los resultados. Por tanto, se ha incluido la opción "Prefiero no especificar" en la variable VE1.2: Género.

Por otra parte, el grado académico del profesor también es visto por algunos expertos como irrelevante, ya que muchos piensan que esto podría ser utilizado para discriminar entre los diferentes grupos de profesores, en función de su formación académica (doctores frente a licenciados, por ejemplo).

\subsection{Preguntas generales sobre enseñanza virtual (bloque 2)}

Este bloque tiene como objetivo conocer la cultura existente, entre estudiantes universitarios de estudios científico-técnicos, sobre el uso de recursos didácticos digitales. Resulta interesante descubrir las posibles diferencias que, sobre el empleo de las TIC en el ámbito educativo, pudieran existir entre distintos grupos de estudiantes, según las distintas variables de identificación descritas en la Tabla 2.

La Tabla 3 resume las preguntas incluidas en este bloque para ambas encuestas, con las aclaraciones pertinentes, en función de la población de que se trate.

Tabla 3. Preguntas generales sobre enseñanza virtual en los dos cuestionarios de requisitos

\begin{tabular}{|c|c|c|}
\hline \# & Variable & Estudiantes \\
\hline VE2.1 & $\begin{array}{l}\text { ¿Tiene conexión a internet en } \\
\text { casa? }\end{array}$ & Sí / No \\
\hline VE2.2 & $\begin{array}{l}\text { Si es así, ¿qué tipo de conexión } \\
\text { tiene? }\end{array}$ & $\begin{array}{l}\text { Fibra Óptica ( } 80 \text { MB o más) / Banda ancha } \\
\text { (hasta } 20 \mathrm{MB} \text { ) / Básica (hasta } 6 \mathrm{Mb} \text { ) / No lo } \\
\text { sé }\end{array}$ \\
\hline VP2.1 & $\begin{array}{l}\mathrm{N}^{\mathrm{o}} \text { de asignaturas presenciales } \\
\text { con apoyo de plataforma digital }\end{array}$ & $0,1,2-3,4-5,>5$ \\
\hline VP4.1 & $\begin{array}{l}\mathrm{N}^{\circ} \text { horas semanales usando la } \\
\text { plataforma digital }\end{array}$ & $1-6 h, 6-12 h, 12-18 h,>18 h$ \\
\hline VP4.2 & $\begin{array}{l}\text { Ubicación preferente de conexión } \\
\text { a la plataforma }\end{array}$ & $\begin{array}{c}\text { Casa / Universidad / Trabajo fuera } \\
\text { Universidad / Otra }\end{array}$ \\
\hline VP4.3 & $\begin{array}{l}\text { Horario preferente de conexión a } \\
\text { la plataforma }\end{array}$ & $\begin{array}{c}8.00-14.00 \mathrm{~h} / 14.00-18.00 \mathrm{~h} / 18.00- \\
20.00 \mathrm{~h} / \text { Después } 20.00 \mathrm{~h}\end{array}$ \\
\hline VS1.1 & $\begin{array}{l}\text { Grado de satisfacción general de } \\
\text { asignaturas presenciales }\end{array}$ & $1-6$ \\
\hline VP3.1 & $\begin{array}{l}\mathrm{N}^{\mathbf{o}} \text { asignaturas totalmente } \\
\text { virtuales } 1\end{array}$ & $0,1,2-3,4-5,>5$ \\
\hline VP3.2 & Plataforma virtual que alojaba las & Página web universidad/ Coursera / Udacity / \\
\hline
\end{tabular}

Validación de requisitos funcionales de un Laboratorio Virtual Remoto como apoyo al blended learning. 


\begin{tabular}{|c|c|c|c|}
\hline & asignaturas presenciales/virtuales & \multicolumn{2}{|c|}{$\begin{array}{c}\text { EdX / Khan Academy / Miriadax / UNED } \\
\text { COMA / Otros }\end{array}$} \\
\hline VP3.3 & $\begin{array}{l}\text { Razones por las que no ha } \\
\text { cursado/impartido ningún curso } \\
\text { virtual }^{1}\end{array}$ & \multirow{3}{*}{\multicolumn{2}{|c|}{ Vid. texto }} \\
\hline VS2.1 & $\begin{array}{l}\text { Razones de mayor satisfacción en } \\
\text { curso(s) totalmente virtuales }{ }^{1}\end{array}$ & & \\
\hline VS2.2 & $\begin{array}{l}\text { Razones de menor satisfacción en } \\
\text { curso(s) totalmente virtuales }{ }^{1}\end{array}$ & & \\
\hline VS2.3 & $\begin{array}{l}\text { Grado de satisfacción con } \\
\text { asignaturas totalmente virtuales }{ }^{1}\end{array}$ & \multicolumn{2}{|r|}{$1-6$} \\
\hline VP3.4 & $\mathrm{N}^{\circ}$ de MOOC como estudiante ${ }^{2}$ & No aplica & $0,1,2-3,4-5,>5$ \\
\hline VP3.5 & $\begin{array}{l}\mathrm{N}^{\mathrm{o}} \text { de MOOC como } \\
\text { instructor/coordinador }\end{array}$ & No aplica & $0,1,2-3,4-5,>5$ \\
\hline VS3.1 & $\begin{array}{l}\text { Razones por las que no ha } \\
\text { participado en ningún MOOC } \\
\text { hasta ahora }\end{array}$ & No aplica & Vid. texto \\
\hline \multicolumn{4}{|c|}{$\begin{array}{l}\text { Estudiantes: asignaturas cursadas; Profesores: asignaturas impartidas (en ambos casos, } \\
\text { en últimos } 12 \text { meses) } \\
{ }^{2} \text { Estudiantes: se considera similar a VP4.1; Profesores: durante los últimos } 12 \text { meses } \\
{ }^{3} \text { VS3.1 se muestra automáticamente si la respuesta a VP3.4 o VP3.5 es } 0\end{array}$} \\
\hline
\end{tabular}

Por consejo de algunos expertos, la pregunta VP3.1: En los últimos 12 meses, ¿cuántas asignaturas/cursos totalmente virtuales ha realizado, a través de alguna plataforma digital?, incluida en el cuestionario de estudiantes, se considera similar a la pregunta VP3.4: Indique cuantos Cursos En Línea Abiertos Masivos (MOOC) ha realizado como estudiante en los últimos 12 meses. La razón es que los estudiantes no tienen por qué saber la distinción entre un MOOC y un curso virtual habitual. Por tanto, esta pregunta se ha eliminado del cuestionario de requisitos de estudiantes.

En el caso de los profesores, dicha pregunta se ha desdoblado en dos: la primera, trata de averiguar el número de MOOCs que los profesores encuestados han realizado como estudiantes (VP3.4); la segunda, pregunta sobre los MOOCs donde el profesor encuestado ha participado como instructor o coordinador (VP3.5). En ambos casos, se ofrecen las siguientes opciones, a valorar entre 1 y 6 :

- VS3.1.1: Aún no se ha dado la ocasión de cursar un MOOC, aunque estaría interesado en hacerlo

- VS3.1.2: No creo en la utilidad de los MOOC como sistema de enseñanza, aunque venga avalado por instituciones de prestigio

- VS3.1.3: Creo que los MOOC ponen en peligro el modelo de enseñanza en el que actualmente trabajo

- VS3.1.4: No tengo tiempo para realizar cursos on-line, adicionales a mis actuales obligaciones académicas/profesionales

- VS3.1.5: No creo en la enseñanza totalmente no presencial. Necesito la interacción en clase con el profesor y/o con otros compañeros

- VS3.1.6: Otras razones (por favor indicar)

Validación de requisitos funcionales de un Laboratorio Virtual Remoto como apoyo al blended learning. 
De igual forma, la pregunta VP3.2: Plataforma digital que alojaba la(s) asignatura(s) presencial(es)/virtual(es), se ha desdoblado como sigue, en el caso del cuestionario de profesores:

- PVP3.2.1: Plataforma digital que alojaba la(s) asignatura(s) presencial(es)

- PVP3.2.2: Plataforma digital que alojaba la(s) asignatura(s) virtual(es)

- PVP3.2.3: Plataforma digital que alojaba el(los) MOOC(s) cursado(s) como estudiante

- PVP3.2.4: Plataforma digital que alojaba el(los) MOOC(s) donde ha participado como instructor/coordinador

A la pregunta VP3.3: Razones por las que no ha realizado/impartido ningún curso totalmente virtual, las opciones propuestas al encuestado son las siguientes:

- VP3.3.1: Mi plan de estudios [Los planes de estudios donde imparto docencia] no contempla[n] la realización de asignaturas no presenciales

- VP3.3.2: Aunque existen asignaturas no presenciales en mi plan de estudios [los planes de estudios donde imparto docencia], he optado por cursar [impartir] la asignatura equivalente de forma presencial

- VP3.3.3: No tengo tiempo para realizar cursos on-line, adicionales a mis actuales obligaciones académicas/profesionales

- VP3.3.4: No creo en la enseñanza totalmente no presencial. Necesito la interacción en clase con el profesor [los estudiantes] y/o con el resto de compañeros

- VP3.3.5: Otras razones (por favor indicar)

Por otra parte, las opciones dadas al encuestado en la pregunta VS2.1: Razones de mayor satisfacción en asignatura( $(s)$ totalmente virtual(es) son:

- VS2.1.1: Área temática

- VS2.1.2: Formato y presentación del curso

- VS2.1.3: Actividades obligatorias

- VS2.1.4: Actividades voluntarias

- VS2.1.5: Flexibilidad de horario para [que los estudiantes puedan] seguir el curso a mi [su] propio ritmo

- VS2.1.6: Actitud del docente/coordinador [de los estudiantes] del curso

- VS2.1.7: Participación de los compañeros [Colaboración con otros colegas]

- VS2.1.8: Otros aspectos (por favor indicar)

Las posibles respuestas a la pregunta VS2.2: Razones de menor satisfacción en asignatura(s) totalmente virtual( $e s)$, a valorar entre 1 y 6 , son las siguientes:

- VS2.2.1: El contenido del curso no ha respondido a las expectativas que tenía [tenían los estudiantes]

- VS2.2.2: El formato y la presentación del curso no eran atractivos [para los estudiantes]

Validación de requisitos funcionales de un Laboratorio Virtual Remoto como apoyo al blended learning. J. Gamo et al. 
- VS2.2.3: Las fechas de entrega para la presentación de trabajos y/o terminación de módulos eran demasiado cortas, e impidieron completar adecuadamente el curso

- VS2.2.4: El curso era demasiado corto, y no permitía profundizar en algunos contenidos

- VS2.2.5: El curso era demasiado largo. Los mismos contenidos se podrían haber impartido en menos tiempo

- VS2.2.6: Las herramientas de la plataforma (foros, correo electrónico, etc.) no permiten la resolución completa de las dudas por parte de los profesores y/o compañeros [estudiantes]

- VS2.2.7: Echo de menos la comunicación presencial con el profesor [los estudiantes]

- VS2.2.8: Echo de menos la interacción personal con los compañeros

- VS2.2.9: La plataforma era muy lenta, a menudo se perdía la conexión, etc.

- VS2.2.10: Otros aspectos (por favor indicar)

4.5 Preguntas específicas sobre enseñanza virtual y cultura colaborativa (bloque 3)

Este bloque pretende averiguar el grado de interés de los encuestados sobre la realización de prácticas virtuales remotas (como complemento a los laboratorios presenciales), las herramientas y funcionalidades deseables en la plataforma, y el grado de cultura colaborativa de los encuestados, pues recordemos que la colaboración es uno de los pilares básicos en los que se pretende asentar la plataforma OPTILAB.

El bloque comienza con la frase "Piense en una asignatura de las que curse [imparta], que contenga prácticas de laboratorio. Si no tiene ninguna, piense en alguna asignatura/carrera que requiera de algún tipo de práctica experimental"'. A continuación, se presentan al encuestado las preguntas recogidas en la Tabla 4.

Tabla 4. Preguntas específicas sobre enseñanza virtual y cultura colaborativa

\begin{tabular}{|c|c|c|}
\hline \# & Variable & \begin{tabular}{|l|l|} 
Estudiantes & Profesores \\
\end{tabular} \\
\hline $\begin{array}{l}\text { VS3. } \\
2\end{array}$ & $\begin{array}{l}\text { ¿La asignatura en cuestión permite algún tipo de } \\
\text { experimentación virtual y/o remota (es decir, } \\
\text { simulaciones en línea, gestión remota de } \\
\text { instrumentos, etc.? }\end{array}$ & Sí / No \\
\hline $\begin{array}{l}\text { VS3. } \\
3\end{array}$ & $\begin{array}{l}\text { ¿Se debe utilizar una plataforma virtual a distancia, } \\
\text { como apoyo a la enseñanza presencial en } \\
\text { laboratorio? }\end{array}$ & $\begin{array}{l}\text { Sí / No. Justifique su } \\
\text { respuesta }\end{array}$ \\
\hline $\begin{array}{l}\text { VS3. } \\
4\end{array}$ & $\begin{array}{l}\text { ¿Alguna vez ha participado en el diseño, prueba y/o } \\
\text { validación de alguna herramienta de enseñanza } \\
\text { digital? }\end{array}$ & Sí / No \\
\hline $\begin{array}{ll}\text { VS4. } \\
1\end{array}$ & $\begin{array}{l}\text { ¿Qué contenidos encuentra más interesantes para } \\
\text { ser incluidos en la plataforma digital? }\end{array}$ & \multirow{2}{*}{ Vid. Resultados } \\
\hline $\begin{array}{l}\text { VS5. } \\
1\end{array}$ & $\begin{array}{l}\text { Valore las herramientas que considere más útiles de } \\
\text { la plataforma virtual }\end{array}$ & \\
\hline $\begin{array}{ll}\text { VS6. } \\
1\end{array}$ & $\begin{array}{l}\text { Valore las herramientas siguientes, en relación con } \\
\text { el conocimiento que tenga de ellas }\end{array}$ & \multirow{2}{*}{$\begin{array}{c}\text { Dropbox / Evernote / } \\
\text { Doodle / Google drive / } \\
\text { Skydrive }\end{array}$} \\
\hline VS6. & Valore las herramientas siguientes, en relación con & \\
\hline
\end{tabular}

Validación de requisitos funcionales de un Laboratorio Virtual Remoto como apoyo al blended learning. 


\begin{tabular}{|l|l|c|}
\hline 2 & el uso que tenga de ellas & \\
\hline $\begin{array}{l}\text { VS6. } \\
3\end{array}$ & Valore su presencia en redes sociales ${ }^{1}$ & $\begin{array}{c}\text { Facebook, Twitter, Tuenti, } \\
\text { Google }+, \text { Linkedin, } \\
\text { Instagram }\end{array}$ \\
\hline $\begin{array}{l}\text { VS6. } \\
4\end{array}$ & ¿Escribe en algún blog? $^{2}$ & Texto libre \\
\hline
\end{tabular}

${ }^{1}$ Si no la conoce, no marque nada

${ }^{2}$ En caso afirmativo, especifique el tema del mismo, y si lo desea, la dirección URL

Las opciones dadas al encuestado en la pregunta VS4.1: ¿Qué contenidos encuentra más interesantes para ser incluidos en la plataforma digital?, a valorar entre 1 y 6 , son las siguientes:

- VS4.1.1: Manual de prácticas, para llevar a cabo las sesiones reales en el aula de laboratorio

- VS4.1.2: Descarga de vídeos de experimentos reales

- VS4.1.3: Cuestiones previas, que sirvan para introducir la sesión experimental que realizará en el aula de laboratorio

- VS4.1.4: Ejercicios de autoevaluación que sirvan para fortalecer el conocimiento de las prácticas en el aula, una vez llevadas a cabo

- VS4.1.5: Software de simulación de los fenómenos en estudio (al que se pueda acceder en cualquier momento, antes / después de la sesión de práctica en el aula de laboratorio)

- VS4.1.6: Realización de experimentos "en vivo" manejando instrumentación real de forma remota, y visualizando los resultados en mi propio ordenador (requiere reservar una franja horaria entre las disponibles)

- VS4.1.7: Otros contenidos (indicar)

Por otra parte, a la pregunta VS5.1: Valore las herramientas que considere más útiles de la plataforma virtual, se ofrecen las siguientes alternativas:

- VS5.1.1: Correo electrónico con el instructor y otros estudiantes

- VS5.1.2: Foros abiertos para el debate, proponer dudas, etc.

- VS5.1.3: Sesiones de chat con el profesor

- VS5.1.4: Enlaces externos para ampliar información

- VS5.1.5: Otras herramientas (por favor indicar)

\section{Resultados}

Los cuestionarios han sido respondidos por 91 profesores y 129 estudiantes, respectivamente. Se presenta el análisis de fiabilidad y validez de los resultados obtenidos; a continuación, se muestra el análisis estadístico de los datos recopilados.

5.1 Análisis de fiabilidad y validez de los cuestionarios

En el análisis de resultados, se ha utilizado el paquete estadístico SPSS, versión 17.0.

Validación de requisitos funcionales de un Laboratorio Virtual Remoto como apoyo al blended learning. 
Respecto a la validez de los cuestionarios, se ha analizado la validez de contenido de las variables incluidas en los cuestionarios. Para ello, se ha solicitado al grupo de jueces de la Tabla 1, que valoren de 1 a 6 la pertinencia de cada variable.

La Tabla 5 muestra los resultados de dicha evaluación. El análisis preliminar de las respuestas aportadas por los jueces, no arrojó diferencias significativas respecto a la procedencia de los mismos (españoles o extranjeros), por lo que se han calculado, de forma integrada, la media y desviación típica de las opiniones formuladas por cada uno de los dos grupos de expertos, atendiendo únicamente a su especialidad.

Tabla 5. Evaluación por expertos de las variables de los cuestionarios de requisitos

\begin{tabular}{|c|c|c|c|c|c|c|c|c|c|c|}
\hline & \multicolumn{5}{|c|}{ EXPERTOS CIENCIAS } & \multicolumn{5}{|c|}{ EXPERTOS EDUCACIÓN } \\
\hline Variables & $\mathbf{N}$ & Min & Max & Mean & Std & $\mathbf{N}$ & Min & Max & $x$ Mean & Std \\
\hline VE1.1 & 14 & 4 & 6 & $5 \quad 5,00$ & 0,68 & 5 & 5 & & 5,40 & 0,55 \\
\hline VE1.2 & 14 & 3 & 6 & $5 \quad 4,00$ & 0,96 & 5 & 4 & & $5 \quad 4,80$ & 0,45 \\
\hline VE1.3 & 14 & 3 & 6 & $5 \quad 4,64$ & 1,28 & 5 & 5 & 6 & $6 \quad 5,80$ & 0,45 \\
\hline VE1.4 & 14 & 4 & 6 & $5 \quad 5,79$ & 0,58 & 5 & 2 & & 65,00 & 1,73 \\
\hline VE2.1 & 14 & 3 & 6 & $5 \quad 5,79$ & 0,80 & 5 & 6 & & $6 \quad 6,00$ & 0,00 \\
\hline VE2.2 & 14 & 2 & 6 & $5 \quad 4,21$ & 1,19 & 5 & 3 & 6 & 65,00 & 1,22 \\
\hline VP1.1 & 14 & 3 & 6 & $5 \quad 4,50$ & 1,22 & 5 & 3 & & 65,00 & 1,22 \\
\hline VP1.2 & 14 & 3 & 6 & $5 \quad 4,50$ & 0,85 & 5 & 4 & & $6 \quad 4,80$ & 0,84 \\
\hline VP1.3 & 14 & 2 & 5 & $5 \quad 3,71$ & 0,83 & 5 & 4 & 6 & 65,00 & 0,71 \\
\hline VP1.4 & 14 & 3 & 6 & $5 \quad 4,07$ & 0,83 & 5 & 2 & & $5 \quad 3,80$ & 1,30 \\
\hline VP2.1 & 14 & 2 & 6 & $5 \quad 4,50$ & 1,09 & 5 & 4 & & $6 \quad 4,80$ & 0,84 \\
\hline VP3.1 & 14 & 3 & 6 & $5 \quad 4,14$ & 0,86 & 5 & 4 & 6 & $6 \quad 4,80$ & 0,84 \\
\hline VP3.2 & 14 & 3 & 6 & $5 \quad 4,14$ & 0,77 & 75 & 3 & & $6 \quad 4,20$ & 1,10 \\
\hline VP3.3.1 & 14 & 2 & 6 & $5 \quad 3,00$ & 1,18 & 35 & 2 & & $6 \quad 3,60$ & 1,52 \\
\hline VP3.3.2 & 14 & 2 & 5 & $5 \quad 3,71$ & 0,91 & 15 & 3 & & $5 \quad 4,00$ & 1,00 \\
\hline VP3.3.3 & 14 & 3 & 6 & $5 \quad 3,93$ & 0,92 & 25 & 3 & & $6 \quad 4,60$ & 1,14 \\
\hline VP3.3.4 & 14 & 3 & 5 & $5 \quad 4,21$ & 0,70 & 5 & 3 & & $5 \quad 4,20$ & 0,84 \\
\hline VP3.3.5 & 14 & 3 & 6 & $5 \quad 4,07$ & 1,07 & 75 & 3 & & $6 \quad 4,20$ & 1,10 \\
\hline VP4.1 & 14 & 4 & 6 & $5 \quad 4,71$ & 0,83 & 35 & 4 & & $6 \quad 4,40$ & 0,89 \\
\hline VP4.2 & 14 & 2 & 6 & $5 \quad 4,36$ & 1,15 & 5 & 5 & & $6 \quad 5,20$ & 0,45 \\
\hline VP4.3 & 14 & 2 & 6 & $5 \quad 4,36$ & 1,08 & 35 & 4 & & $6 \quad 4,60$ & 0,89 \\
\hline VS1.1 & 14 & 4 & 6 & $5 \quad 4,93$ & 0,73 & 35 & 5 & & $6 \quad 5,60$ & 0,55 \\
\hline VS2.1.1 & 14 & 3 & 6 & $5 \quad 5,57$ & 0,85 & 5 & 6 & & $6 \quad 6,00$ & 0,00 \\
\hline VS2.1.2 & 14 & 4 & 6 & $5 \quad 5,14$ & 0,66 & 5 & 5 & & $6 \quad 5,40$ & 0,55 \\
\hline VS2.1.3 & 14 & 5 & 6 & $5 \quad 5,36$ & 0,50 & 5 & 5 & & $6 \quad 5,40$ & 0,55 \\
\hline VS2.1.4 & 14 & 4 & 6 & $5 \quad 5,00$ & 0,68 & 35 & 4 & & $6 \quad 5,00$ & 1,00 \\
\hline VS2.1.5 & 14 & 4 & 6 & $5 \quad 4,93$ & 0,62 & 25 & 4 & & $6 \quad 4,80$ & 0,84 \\
\hline VS2.1.6 & 14 & 5 & 6 & $5 \quad 5,64$ & 0,50 & 5 & 5 & & $6 \quad 5,60$ & 0,55 \\
\hline VS2.1.7 & 14 & 4 & 6 & $5 \quad 5,07$ & 0,62 & 25 & 4 & & $6 \quad 5,20$ & 0,84 \\
\hline VS2.1.8 & 14 & 2 & 5 & $5 \quad 3,29$ & 0,99 & 5 & 3 & & $5 \quad 3,80$ & 0,84 \\
\hline VS2.2.1 & 14 & 4 & 6 & $5 \quad 5,64$ & 0,63 & 35 & 6 & & $6 \quad 6,00$ & 0,00 \\
\hline VS2.2.2 & 14 & 4 & 6 & $5 \quad 5,43$ & 0,65 & 5 & 5 & & $6 \quad 5,40$ & 0,55 \\
\hline VS2.2.3 & 14 & 4 & 6 & $5 \quad 5,14$ & 0,66 & 55 & 4 & & $5 \quad 4,60$ & 0,55 \\
\hline VS2.2.4 & 14 & 5 & 6 & $5 \quad 5,64$ & 0,50 & 5 & 5 & & $6 \quad 5,60$ & 0,55 \\
\hline VS2.2.5 & 14 & 4 & 6 & $5 \quad 5,00$ & 0,68 & 35 & 4 & 6 & $6 \quad 4,80$ & 0,84 \\
\hline VS2.2.6 & 14 & 4 & 6 & $5 \quad 5,07$ & 0,73 & 35 & 5 & & $6 \quad 5,60$ & 0,55 \\
\hline VS2.2.7 & 14 & 3 & 5 & $5 \quad 4,21$ & 0,70 & 5 & 5 & & $6 \quad 5,40$ & 0,55 \\
\hline VS2.2.8 & 14 & 4 & 6 & $5 \quad 5,29$ & 0,73 & 35 & 5 & & $6 \quad 5,40$ & 0,55 \\
\hline VS2.2.9 & 14 & 4 & 6 & $5 \quad 5,07$ & 0,62 & 25 & 5 & & $6 \quad 5,60$ & 0,55 \\
\hline VS2.2.10 & 14 & 4 & 6 & $5 \quad 5,21$ & 0,58 & 35 & 5 & & $6 \quad 5,60$ & 0,55 \\
\hline
\end{tabular}

\begin{tabular}{|c|c|c|c|c|c|c|c|c|c|c|}
\hline \multicolumn{6}{|c|}{ EXPERTOS CIENCIAS } & \multicolumn{5}{|c|}{ EXPERTOS EDUCACIÓN } \\
\hline & $\mathbf{N}$ & Min & Max & Mean & Std & $\mathbf{N}$ & Min & Max & Mean & Std \\
\hline & 14 & & 5 & 13 & 0,65 & 3 & & $\sigma$ & O & 1,14 \\
\hline & 14 & & & 4,79 & 0,89 & 5 & & 6 & 00 & 0,71 \\
\hline & 14 & & & 6 & 1,03 & 5 & & & & 0,45 \\
\hline & 14 & & & 4 & 0,84 & 5 & & & & 1,10 \\
\hline 3 & 14 & 3 & 6 & 3,93 & 1,14 & 5 & & 6 & 20 & 1,30 \\
\hline & 14 & & & 6 & & 5 & & & & 0,84 \\
\hline & 14 & & 6 & 6 & & 5 & & & & 0,00 \\
\hline & 14 & 2 & & 3,50 & 0,85 & 5 & & 6 & 40 & 0,55 \\
\hline 3 & 14 & . & 5 & 5 & 0 & 5 & & 6 & 0 & 1,34 \\
\hline & 14 & 2 & & 6 & & 5 & & & 5 & 1,30 \\
\hline & 14 & 2 & & 5 & 0,73 & 5 & & 5 & 80 & 1,10 \\
\hline .1 .6 & 14 & & & 5 & & 5 & & 6 & 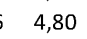 & 1,10 \\
\hline & 14 & 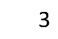 & & 5 & 0,55 & 5 & & & 40 & 0,89 \\
\hline & 14 & 4 & 6 & 6 & 0,76 & 5 & & 6 & 00 & 0,00 \\
\hline & 14 & & & 5 & & 5 & & & & 0,84 \\
\hline & 14 & 2 & & 5 & 0 & 5 & & 3 & 80 & 0,45 \\
\hline & 14 & 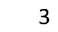 & 6 & 6 & 0,94 & 5 & & & 0 & 0,89 \\
\hline & 1 & & & 6 & & 5 & & & & 0,84 \\
\hline & 14 & 3 & 6 & 6 & 0,94 & 5 & & 5 & 60 & 1,95 \\
\hline & 14 & & 6 & 4 & & 5 & & 5 & 0 & 0,89 \\
\hline & 1 & & & 5 & & 5 & & & & 1,14 \\
\hline & 14 & 2 & & 4 & 0,86 & 5 & & 5 & 60 & 0,89 \\
\hline & 14 & & 6 & 6 & & 5 & & 6 & 5 & 1,30 \\
\hline & 1 & & & 6 & & 5 & & 6 & & 1,30 \\
\hline & 14 & 2 & 5 & 36 & 0,93 & 5 & & 6 & 80 & 1,64 \\
\hline & 14 & ? & 5 & $5 \quad 3,50$ & & 5 & & 5 & 5 & 1,10 \\
\hline & 1 & 2 & & 5 & & 5 & 2 & 3 & 0 & 1,10 \\
\hline .2 .5 & 14 & 2 & 5 & 71 & 1,07 & 5 & 2 & 5 & 20 & 1,10 \\
\hline & 14 & ר & 6 & 63 & & 5 & & 6 & 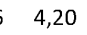 & 1,79 \\
\hline & 14 & 2 & 5 & $5 \quad 3$ & 1,01 & 5 & P & 5 & 80 & 1,10 \\
\hline & 14 & 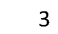 & 5 & 3,93 & 0,73 & 5 & 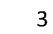 & 5 & 20 & 0,84 \\
\hline & 14 & 2 & 5 & 57 & 0,94 & 5 & & 5 & 60 & 0,89 \\
\hline & 14 & 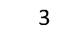 & 5 & 3,86 & 0,86 & 5 & 3 & 5 & 3,80 & 1,10 \\
\hline & 14 & 2 & 5 & $5 \quad 3,79$ & 1,05 & 5 & 3 & 5 & 3,60 & 0,89 \\
\hline & 1 & 2 & 6 & 3 & & 5 & J & 6 &, 00 & 1,22 \\
\hline & 14 & 2 & 5 & 3,43 & 1,02 & 5 & 3 & 5 & 3,80 & 0,84 \\
\hline & 14 & 2 & 5 & $5 \quad 3,071$ & 0,7 & 5 & 3 & 4 & 3,4 & 0,5 \\
\hline VS3.1 & 14 & 3 & 6 & $6 \quad 4,286$ & 0,9 & 5 & 4 & 6 & 5 & 0,7 \\
\hline
\end{tabular}

A la vista de los valores obtenidos, se puede afirmar que la media aritmética supera, en todos los casos, al menos el valor medio de la escala (3.00), lo que confirma la validez del contenido de todos los ítems incluidos en los dos cuestionarios.

Para el análisis de la fiabilidad de los dos cuestionarios de requisitos, se ha calculado el alfa de Cronbach de los elementos tipificados en los cuestionarios (Cronbach, 1951). La Tabla 6 muestra los resultados obtenidos. En cada caso, se han eliminado las variables con varianza nula para el cálculo. Como puede observarse, en ambos casos el alfa de 
Cronbach calculado supera el valor de 0,7 , lo que nos permite afirmar que el grado de fiabilidad de los cuestionarios es excelente (George \& Mallery, 1994).

Tabla 6. Alfa de Cronbach del cuestionario de requisitos de (a) estudiantes (b) profesores

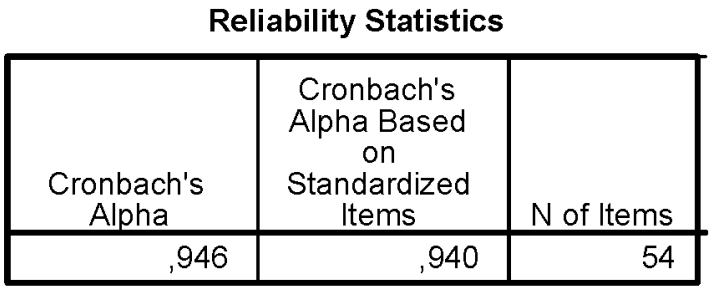

(a)

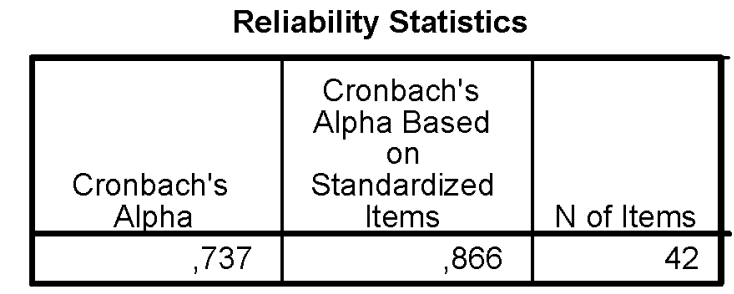

(b)

5.2 Análisis estadísticos de los datos

La mayoría de los profesores encuestados están en la franja 40 - 50 años (40\%), seguido de la banda 50 - 60 años (29\%). En los estudiantes, la población más frecuente es la de 20 años (24\%), seguidos de 19 y 21 años (15\% en ambos casos). El género masculino es el más común (71\% en los profesores; $65 \%$ para los estudiantes). El $4 \%$ de profesores y $2 \%$ de estudiantes prefirieron no especificar el género.

Respecto a la institución de donde provienen los encuestados, como muestra la Figura 2 la mayor frecuencia de estudiantes encuestados provienen de la Universidad de Alcalá, seguido de la Universidad Rey Juan Carlos. Algunas de las universidades inicialmente previstas, no han respondido al cuestionario. Otras, no previstas inicialmente, sí que lo han hecho, especialmente Lafallete College. Respecto a los profesores, la institución con más participantes declarados ha sido Saint Louis University, en su campus principal de St. Louis, Missouri. Es interesante comprobar que varios profesores encuestados realizan su labor docente en empresas tecnológicas y centros de investigación no contemplados inicialmente, lo que aporta una visión complementaria a la opinión que pueden tener los profesores universitarios.

La mayoría de estudiantes cursan Ingeniería de Telecomunicación (23\%), seguida de Ingeniería Mecánica (22\%). En el apartado “Otros", es de resaltar la especialidad de Ingeniería de Materiales (inicialmente no contemplada). Las carreras más frecuentes donde imparten docencia los profesores encuestados son las especialidades de Ingeniería Eléctrica/Electrónica (27\%), Telecomunicación (24\%) e Ingeniería Informática (23\%). En el apartado "Otros", destacan Educación (7\%) y Matemáticas $(6 \%)$, lo que, nuevamente, da una perspectiva mayor que las aportaciones realizadas únicamente por los profesores de ciencias experimentales e ingenierías.

El curso más frecuente donde se hallan matriculados los estudiantes encuestados es $3^{\circ}$ (47\%), seguido por $2^{\circ}(26 \%)$ y $4^{\circ}(23 \%)$. Esto era de prever, a tenor de los resultados de edad registrados. Respecto a los profesores, la frecuencia mayor sucede para docencia superior al $5^{\circ}$ curso, es decir, doctorado (47\%), seguida del $3^{\circ}$ curso $(38 \%)$.

Respecto a la ocupación principal, la mayoría de los estudiantes encuestados se dedican únicamente a estudiar (75\%), mientras que el $25 \%$ estudian y trabajan a la vez. Al analizar en detalle la ocupación principal, el 56\% se declaran estudiantes a tiempo 
completo, mientras que el $18 \%$ son estudiantes que buscan un empleo. La mayoría de profesores $(65 \%)$ lo son a tiempo completo. El apartado "Otros"' representa un 14\%, lo que no es desdeñable, si bien algunas de las figuras señaladas (por ejemplo, Adjunct Professor), podrían corresponder a lo que en España entendemos como profesor asociado a tiempo parcial.

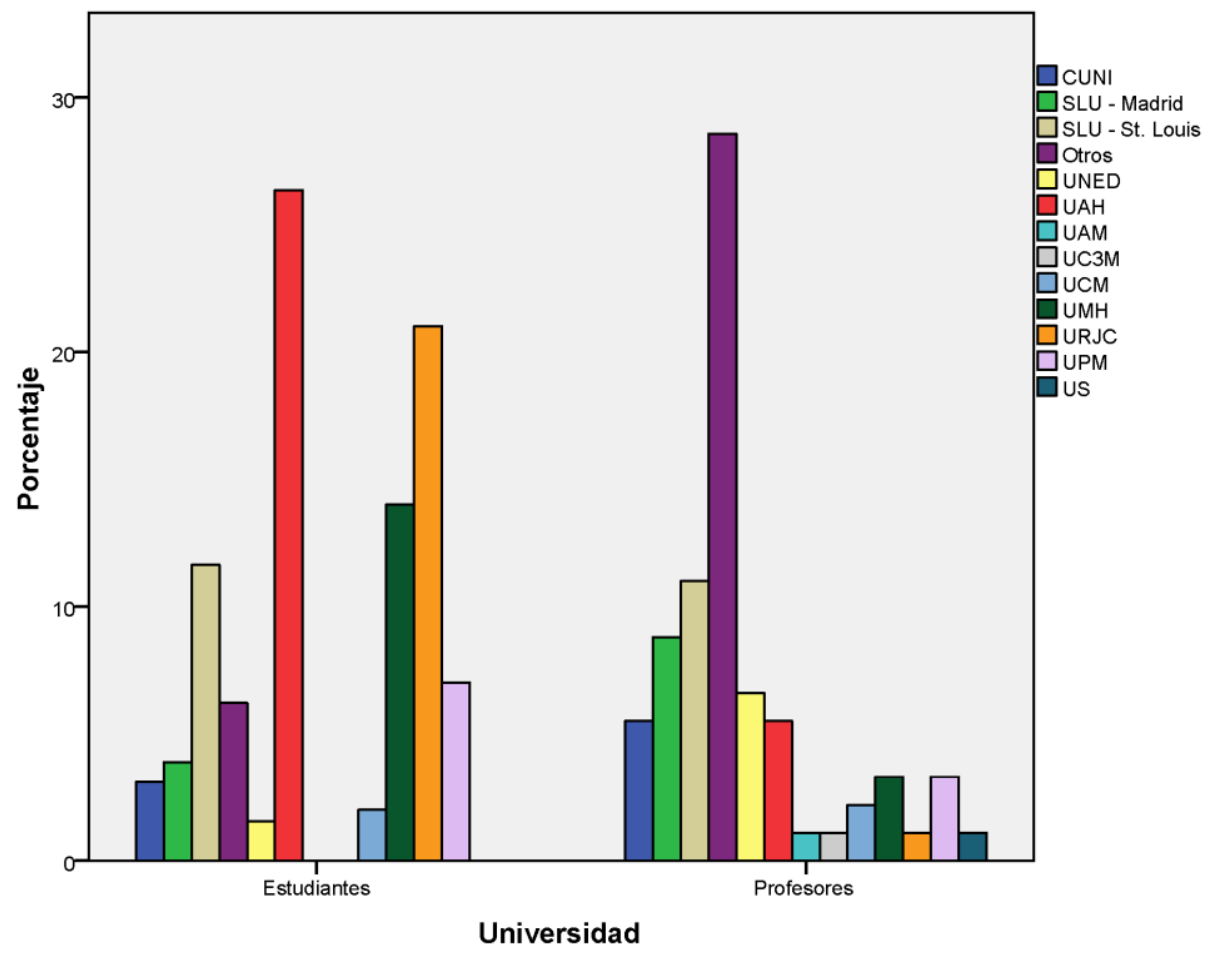

Figura 2. Resultados de la variable VP1.1: Universidad para estudiantes y profesores
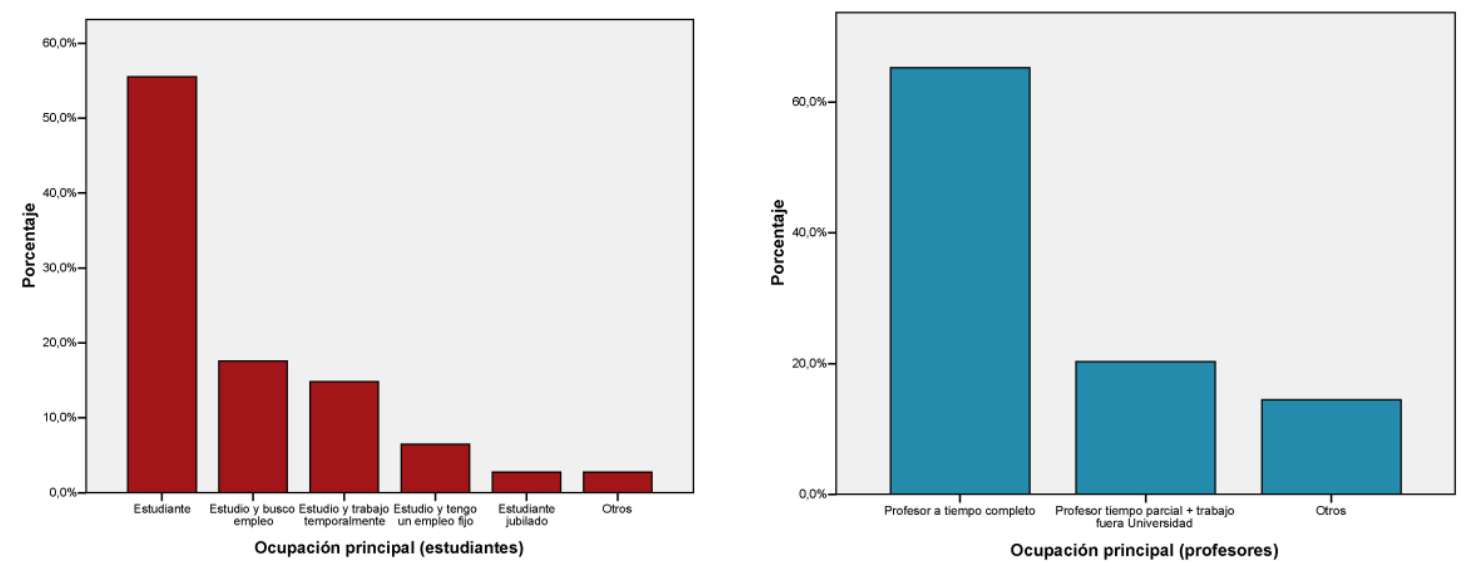

Figura 3. Resultados de la variable VE1.4: Ocupación principal para estudiantes y profesores

Respecto a las preguntas del bloque 2, el $99 \%$ del profesorado y $97 \%$ de estudiantes disponen de acceso a internet en casa. En el Tipo de conexión a internet indicado en la Figura 4, un gran porcentaje ( $45 \%$ de profesores, $41 \%$ en el caso de estudiantes) dispone de banda ancha (20 MB), y un $29 \%$ de profesores (26\% de estudiantes) afirma tener fibra óptica. Estas cifras consolidan la idea de que la plataforma OPTILAB puede incluir aplicaciones/servicios que requieran gran ancho de banda (por ejemplo, 
simulaciones complejas, video-streaming, etc.). Pocos profesores (3\%) afirman no conocer el tipo de conexión a internet de que disponen en casa, lo que contrasta con el $16 \%$ de estudiantes en la misma situación. Parece claro que el profesorado es consciente del tipo de conexión a internet que contrata, frente a los estudiantes, que muchas veces, reciben este servicio de sus padres (si continúan en la vivienda familiar), o arrendadores (si viven en residencias universitarias o pisos de estudiantes).

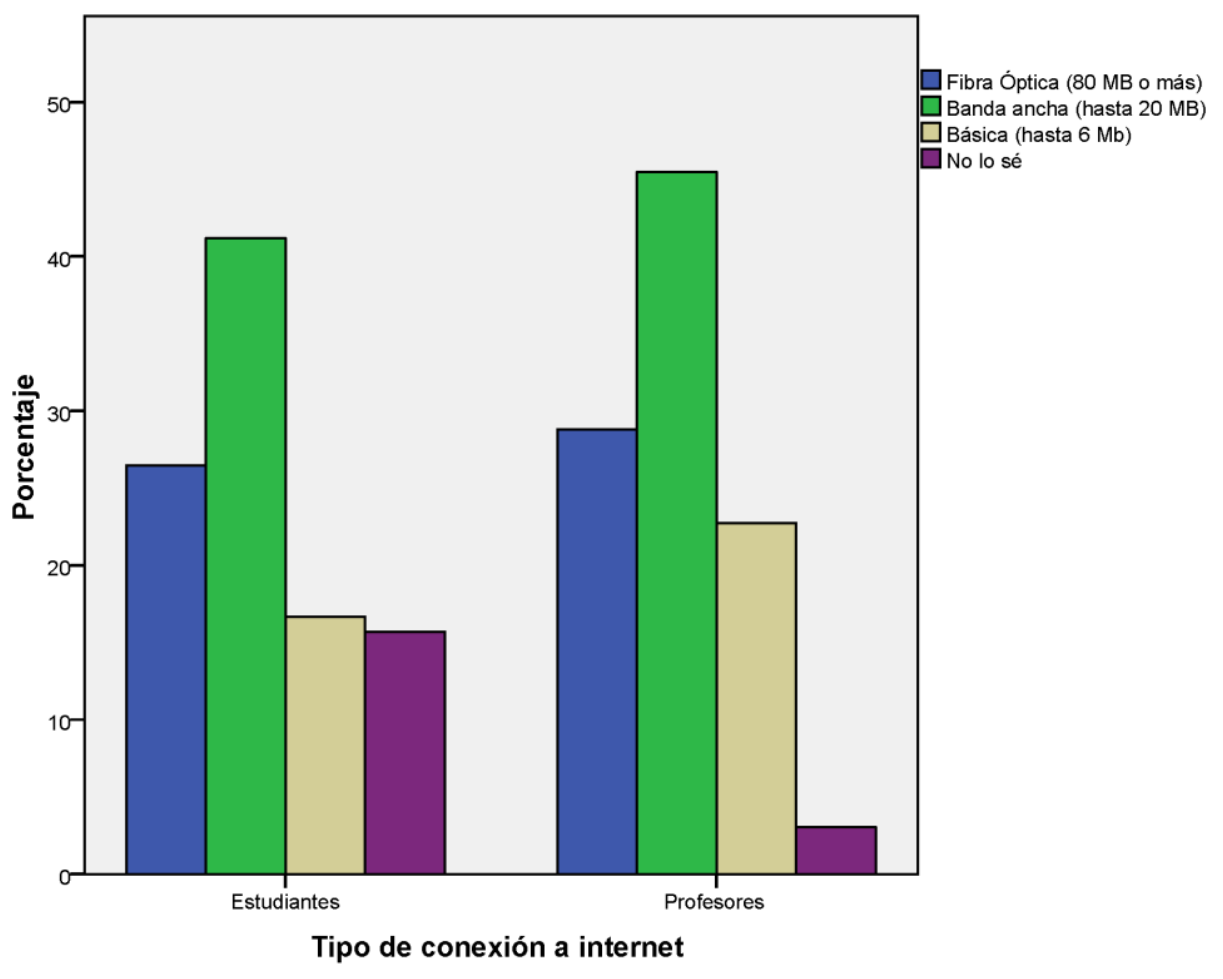

Figura 4. Resultados de la variable VE2.2: Tipo conexión a internet para estudiantes y profesores

La Figura 5 muestra que la mayoría de los estudiantes suelen tener más de 5 asignaturas presenciales. Esto no es muy sorprendente, especialmente con los nuevos planes de estudio, que incluyen asignaturas semestrales. El número de estudiantes que no han cursado asignaturas $(21 \%)$ corresponde a antiguos estudiantes recién titulados, que han participado voluntariamente, rellenando este cuestionario.

En lo que respecta a los profesores, la Figura 5 indica como opción más habitual que cada profesor imparta 2 - 3 asignaturas por año (33\%). Esta tendencia, al menos en la universidad española, está relacionada con la proliferación de la oferta de titulaciones, junto con el crecimiento de facultades y escuelas que se ha producido en los últimos años. Resalta también que un $17 \%$ afirma no haber impartido ninguna asignatura en el último año; esto se debe, fundamentalmente, a que el profesional encuestado tiene otra actividad principal (investigador, profesor asociado, etc.), y se da la circunstancia de que, en el último año, este profesorado no ha ejercido labor docente, si bien la ha realizado en el pasado, y se espera que continúe realizándola en el futuro.

Las dos poblaciones muestran cifras muy similares en el número de cursos totalmente virtuales: la mayoría de estudiantes (75\%) y profesores (64\%) no cursaron/impartieron ningún curso totalmente virtual en los últimos 12 meses. El segundo caso más frecuente

Validación de requisitos funcionales de un Laboratorio Virtual Remoto como apoyo al blended learning. J. Gamo et al. 
es el de profesores que impartieron 2 - 3 cursos virtuales en el último año (17\%). Dado que la única universidad a distancia declarada es la UNED (con un $8 \%$ de la población de profesorado encuestado), el que haya más del doble de profesores habiendo impartido 2 - 3 cursos virtuales en el último año, parece confirmar la tendencia en universidades tradicionales a implantar asignaturas plenamente virtuales, como parte de sus programas docentes.

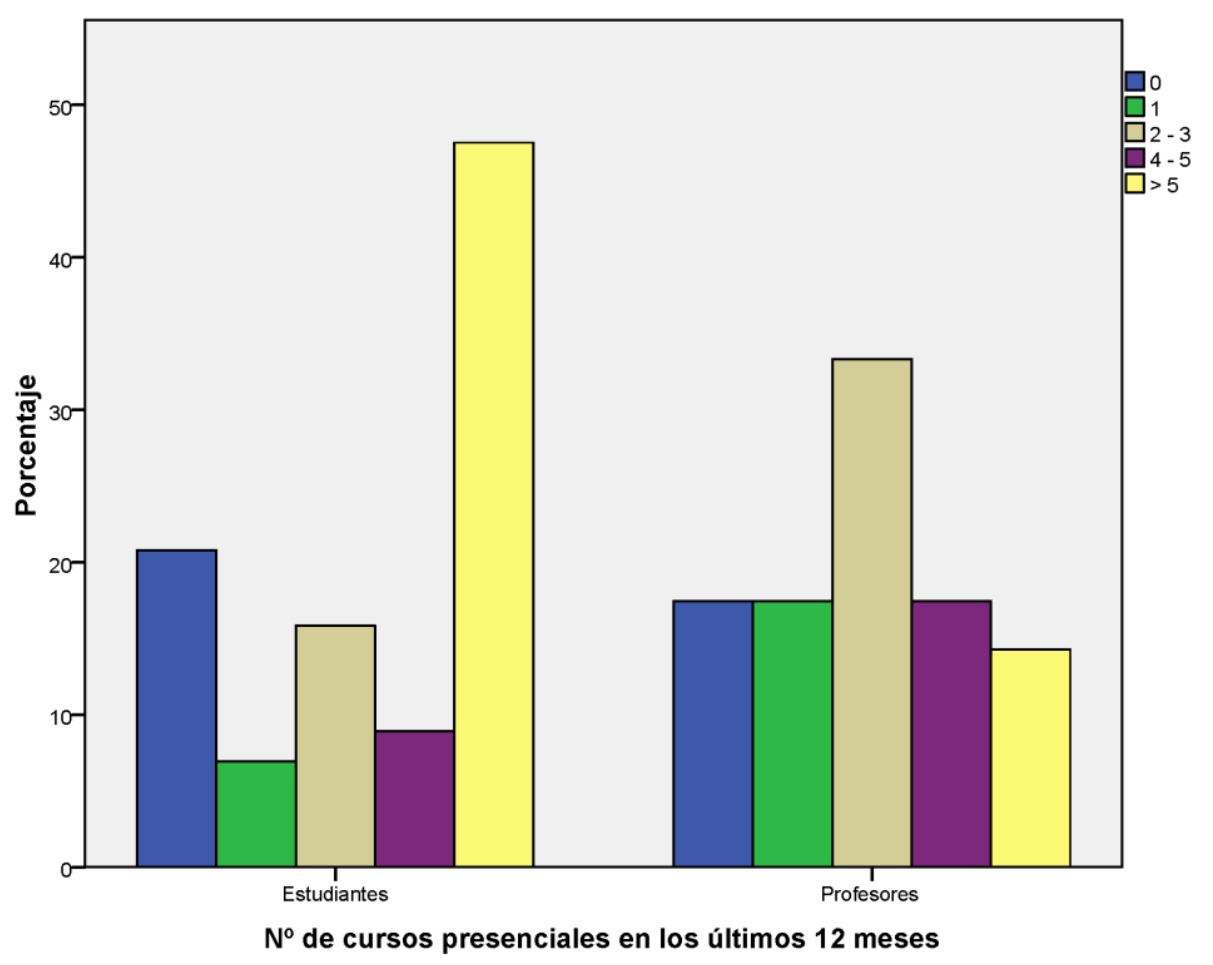

Validación de requisitos funcionales de un Laboratorio Virtual Remoto como apoyo al blended learning. J. Gamo et al. 
Figura 5. Resultados de la variable VP2.1: $N^{o}$ asignaturas presenciales para estudiantes y profesores

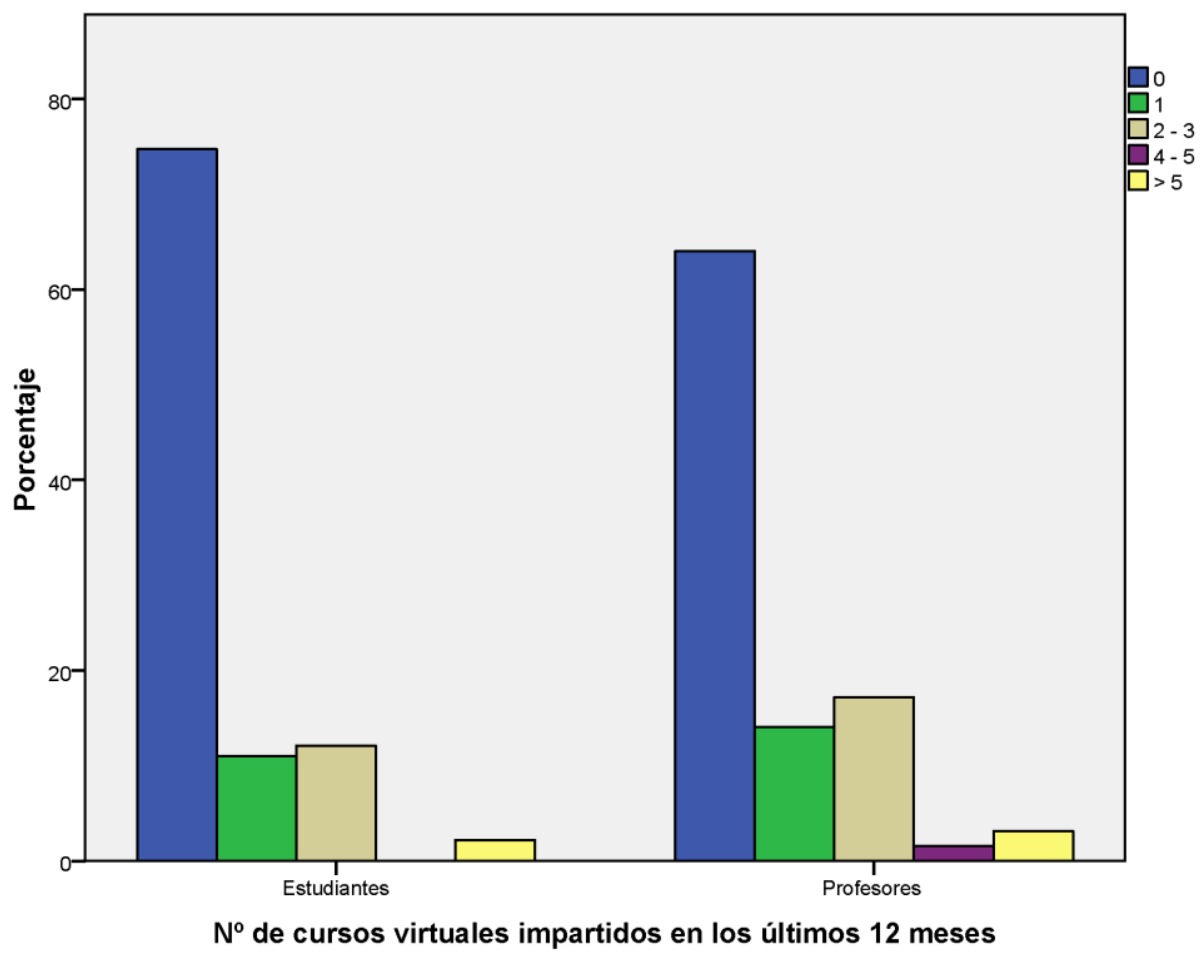

Figura 6. Resultados de la variable VP3.1: $N^{o}$ asignaturas virtuales para estudiantes y profesores

Respecto al tiempo de uso de la plataforma digital, la opción más frecuente es la que dedica entre 1 - 6 horas semanales a conectarse a la plataforma (56\% en el caso de estudiantes, $54 \%$ para profesores), y el mismo porcentaje en ambos casos (28\%) dedican entre 6 - 12 horas. Esto coincide con el hecho de que predominan las asignaturas presenciales, donde la plataforma digital sirve como recurso de apoyo a la docencia (seguramente para descargar el temario, subir tareas de evaluación, etc.).

En lo referente a la ubicación preferente de conexión a la plataforma, los resultados se muestran en la Figura 7. La mayoría de estudiantes prefieren conectarse desde casa (5.36 puntos). Es interesante analizar también el apartado "Otros", que obtuvo la segunda mayor puntuación (4.00 puntos), y que arrojó los siguientes resultados:

- Desde el móvil

- Desde la tableta

- Desde otra universidad

En la época actual, parece claro que los estudiantes no necesitan estar ligados a un sitio fijo para conectarse a la red. Este modelo de conectividad ubicua, utilizando móvil o tableta, lo trasladan también al ámbito académico, por lo que conviene tenerlo en cuenta, de cara a diseñar contenidos que puedan visualizarse adecuadamente en dispositivos móviles.

En el caso de los profesores, se invierte ligeramente la tendencia frente a los

Validación de requisitos funcionales de un Laboratorio Virtual Remoto como apoyo al blended learning. J. Gamo et al. 
estudiantes; ahora, la mayor frecuencia corresponde a la conexión desde las instalaciones universitarias (4.80 puntos), seguida de cerca por la conexión desde casa (4.64 puntos). Esto parece en cierta forma lógico, toda vez que los profesores realizan su actividad profesional fundamentalmente en las dependencias universitarias (al menos los que se dedican a tiempo completo a la vida académica). Como ocurría con los estudiantes, en el apartado "Otros" se ha indicado también la opción:

- Desde la tableta móvil

lo que vuelve a incidir en la ubicuidad de la conexión, que deberá tenerse en cuenta, de cara al diseño de la plataforma VRL.

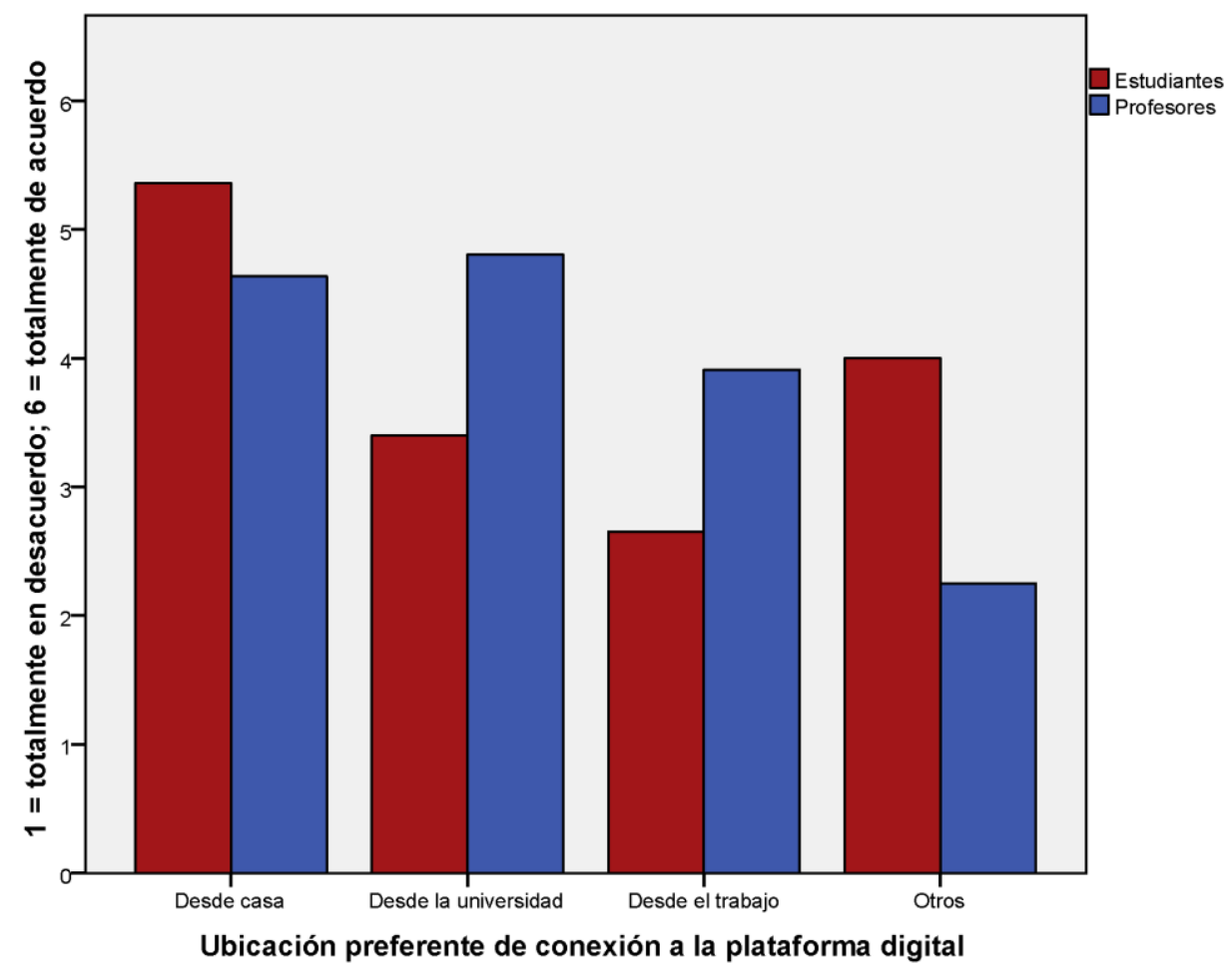

Figura 7. Resultados de la variable VP4.2: Ubicación preferente de conexión a la plataforma para estudiantes y profesores

Respecto al Horario preferente de conexión a la plataforma, como puede observarse en la Figura 8, la mayoría de los estudiantes encuestados utilizan la plataforma digital preferentemente en la franja $18.00 \mathrm{~h}-20.00 \mathrm{~h}$ (4.49 puntos), seguida de la franja a partir de las 20.00h (3.97 puntos). Esta información es muy relevante, de cara al diseño de la plataforma digital, que debe ser lo más robusta posible, para intentar que no deje de funcionar en estos horarios de máxima actividad. Asimismo, las inevitables labores de mantenimiento deberán planificarse preferentemente fuera de estos horarios vespertinos de utilización preferente. 


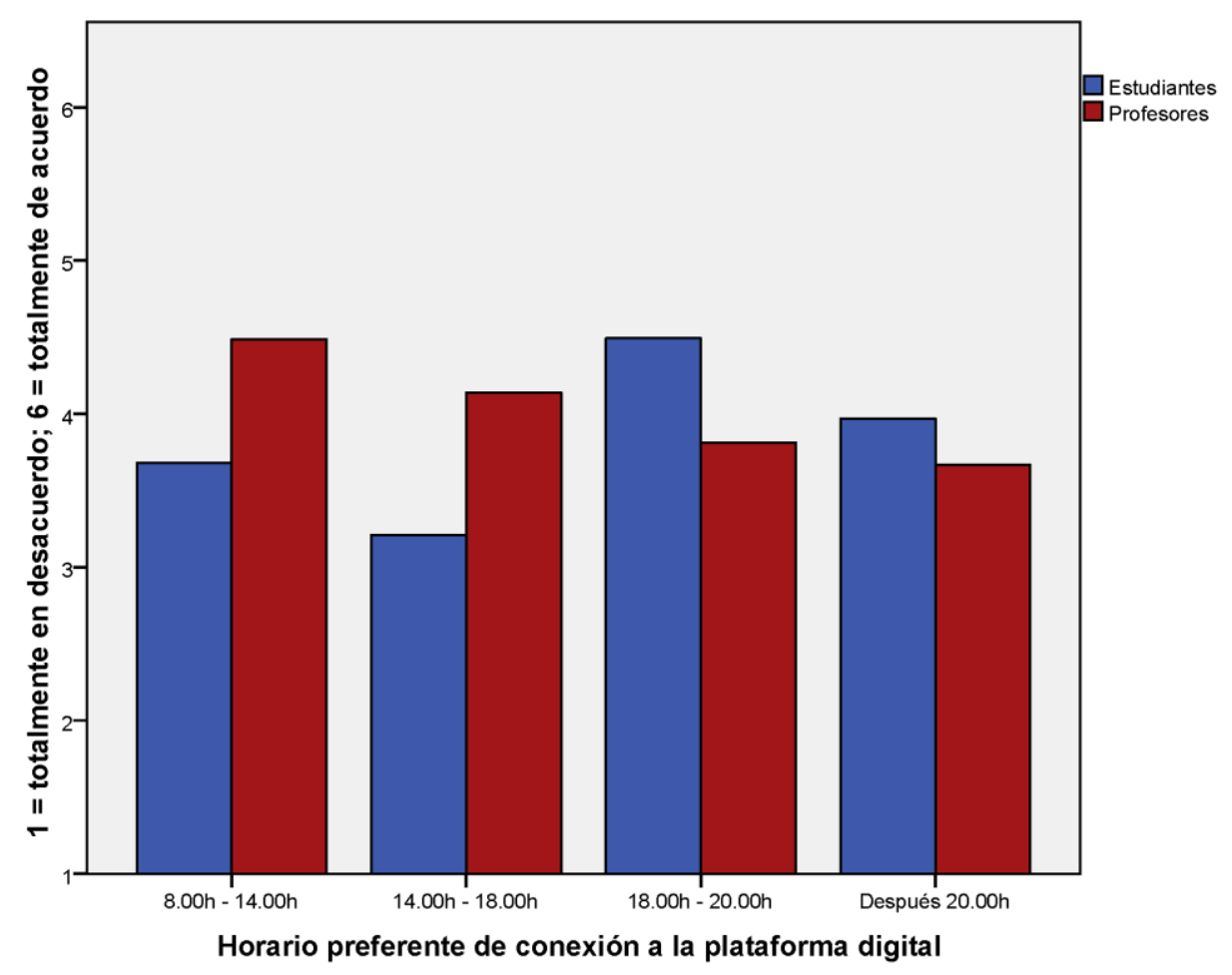

Figura 8. Resultados de la variable VP4.3: Horario preferente de conexión a la plataforma para estudiantes y profesores

Respecto a los profesores, existe un cambio total frente a la opinión vertida por los estudiantes. Tal y como aparece en la Figura 8, la mayor frecuencia de utilización de la plataforma digital por parte de los profesores se realiza en horario de $8.00 \mathrm{~h}-14.00 \mathrm{~h}$ (4.49 puntos), lo que contrasta claramente con la franja de máxima preferencia de los estudiantes (18.00h - 20.00h, también valorada con 4.49 puntos). Esto es bastante lógico, toda vez que, de nuevo, los profesores realizan su labor docente en jornada matutina (especialmente los que trabajan a tiempo completo), y evidentemente, la conexión con la plataforma digital es parte de su trabajo diario. Esto nos debe motivar aún más a que el diseño de la plataforma VRL sea lo más robusta posible, para tener una buena experiencia de usuario, en todas las franjas horarias, y reservando las labores de mantenimiento a noches o fines de semana, siempre que sea posible.

Los motivos para no recibir/impartir asignaturas totalmente virtuales por parte de los encuestados se reflejan en la Figura 9. En el caso de los estudiantes, se ha añadido la opción "No tengo tiempo para recibir cursos on-line adicionales", pues como se ha comentado anteriormente, en el caso de los estudiantes, los expertos aconsejaron no diferenciar entre cursos virtuales reglados y MOOCs. También en el caso de los estudiantes, la opción "Otras razones" fue contestada únicamente por 4 de ellos, por lo que, aunque aparece con gran valor (5.25 puntos de valor medio en la escala Likert de 1 a 6 puntos), no tiene el mismo peso que las demás respuestas.

En ambos casos, la principal razón aportada por los encuestados es que "Mi plan de estudios [Los planes de estudios donde imparto docencia] no contempla[n] la realización de asignaturas no presenciales" (valor medio de 4.68 y 5.06 puntos, respectivamente, en la escala Likert de 1 a 6 puntos).

Validación de requisitos funcionales de un Laboratorio Virtual Remoto como apoyo al blended learning. J. Gamo et al. 
Ambos colectivos también coinciden en señalar "No creo en la enseñanza totalmente no presencial. Necesito la interacción en clase con el profesor [los estudiantes] y/o con el resto de compañeros" como la segunda de las razones más valoradas (3.79 puntos en el caso de los estudiantes; 3.97 puntos por parte de los profesores). Esto es algo que debe tenerse en cuenta a la hora de diseñar la plataforma de VRL como un complemento (y no sustitución) a las sesiones tradicionales en el laboratorio presencial, tal y como se corroborará más adelante.

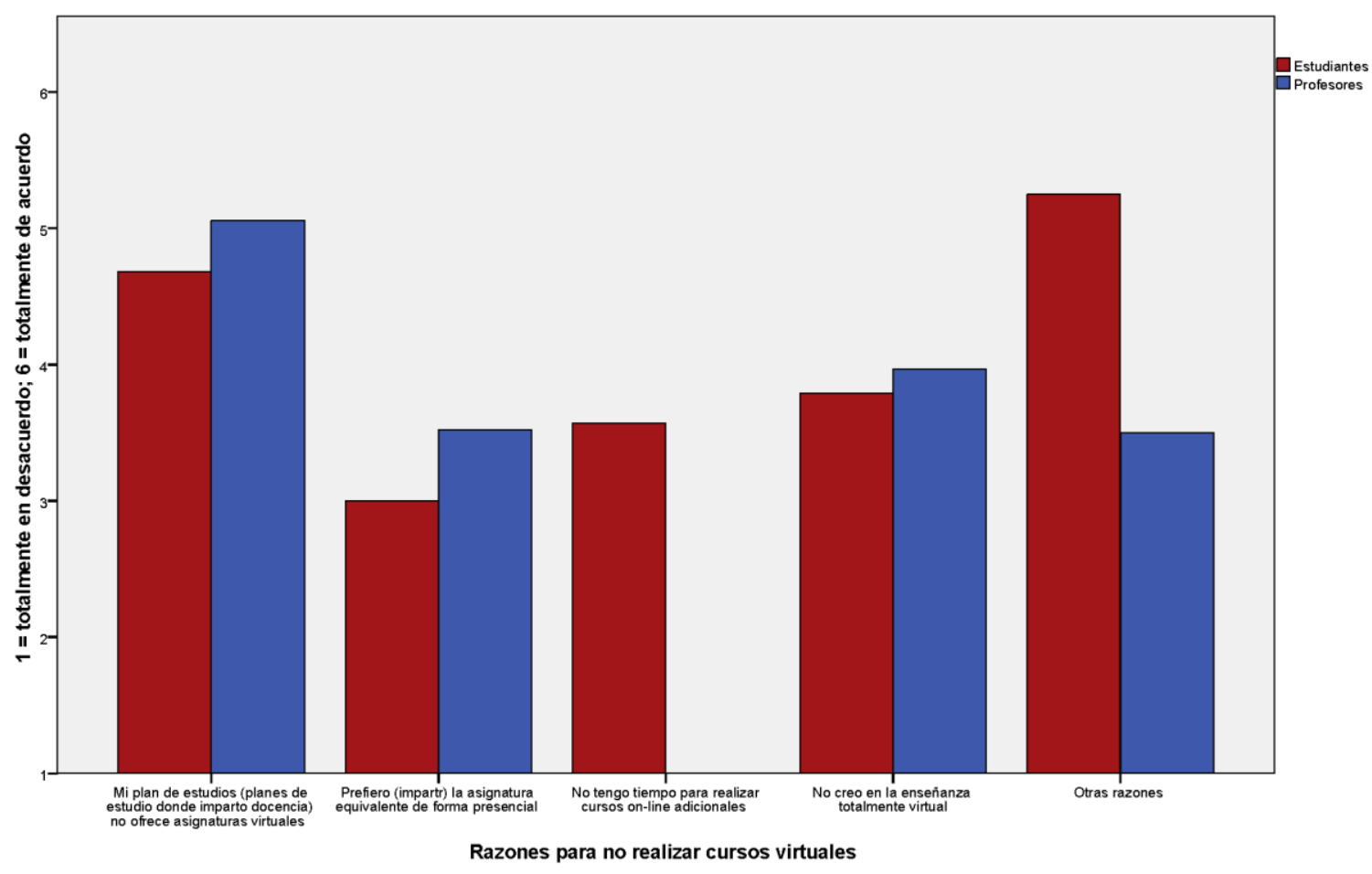

Figura 9. Resultado de la variable VP3.3: Razones por las que no ha impartido ningún curso virtual, para estudiantes y profesores

En el apartado “Otras razones", se señalaron las siguientes:

\section{Estudiantes:}

- Cursé el sistema docente antiguo. Valoro mucho los cursos virtuales y pienso que los laboratorios virtuales serían un avance.

- No conozco ningún curso virtual, y no me gusta la idea de los mismos.

\section{Profesores:}

- No es mi dedicación principal en este momento.

- En este momento, mi institución no ofrece cursos virtuales. Algunos compañeros han comenzado a usar el modelo de clase invertida (Strauss, 2012), el cual es ineficiente para clases de laboratorio.

En este sentido, se han realizado estudios sobre ejemplos de enseñanza a distancia en entornos masivos, comparando métodos eLearning puros, con enseñanza a distancia tradicional, en estudios de ciencias informáticas (Carswell, 2000). El resultado es que no hay cambio en la calidad de la enseñanza por ser totalmente "electrónica". 
Respecto a las "Razones de mayor satisfacción en asignaturas virtuales", la Figura 10 muestra los resultados obtenidos, en el caso de estudiantes. La razón mejor valorada es la "Flexibilidad de horario para poder seguir la asignatura al ritmo deseado" (5.05 puntos de promedio), seguida de la "Actitud del profesor/coordinador del curso virtual" (5.00 puntos). En esto último, parece claro que la actitud del profesorado sigue siendo clave de cara al éxito y satisfacción del alumnado, independientemente de que se trate de enseñanza presencial o virtual.

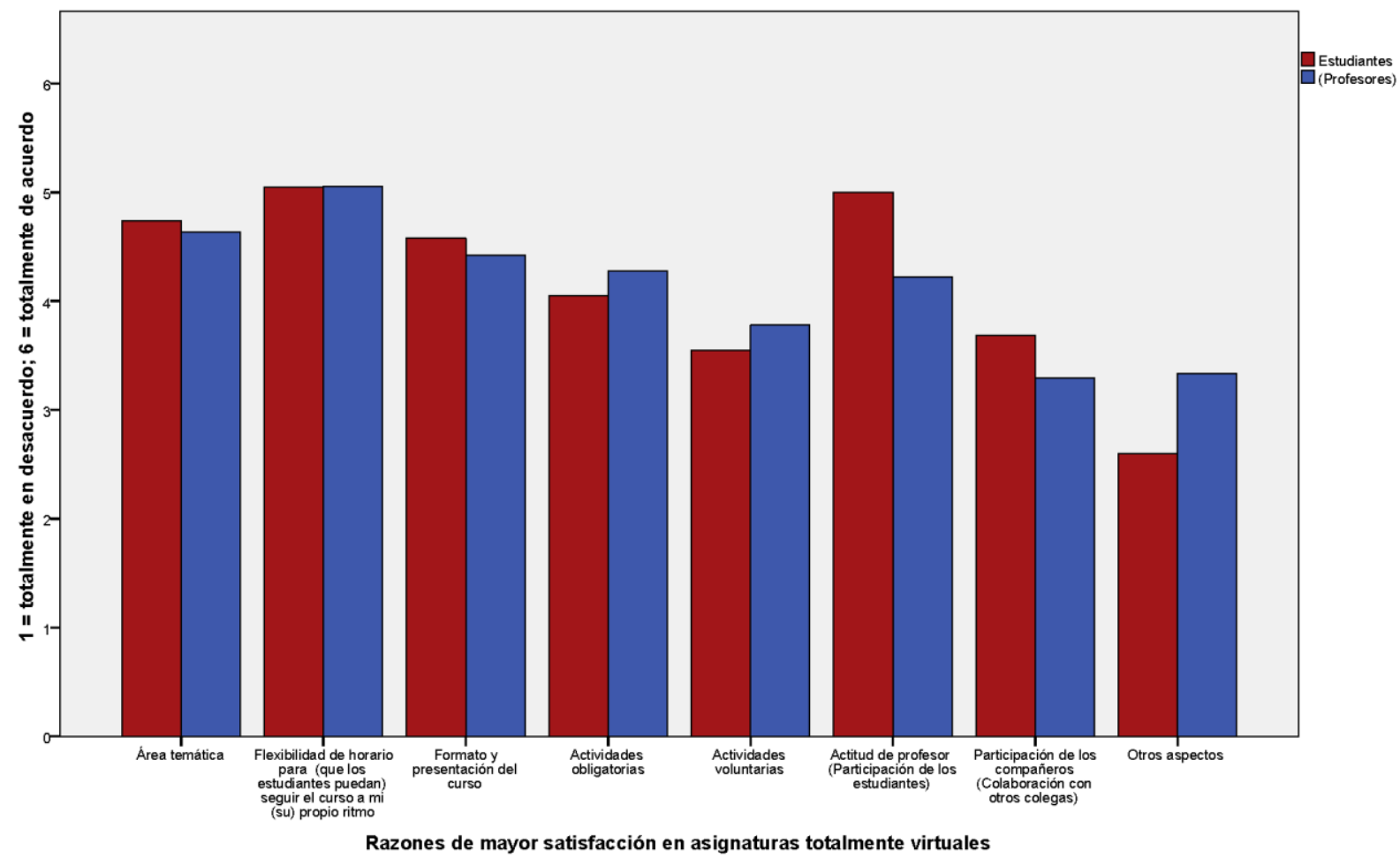

Figura 10. Resultado de la variable VS2.1: Razones de mayor satisfacción en asignatura(s) totalmente virtual(es) para estudiantes y profesores

En el caso de los profesores, y como ocurría con los estudiantes, la "Flexibilidad de horario para poder seguir la asignatura al ritmo deseado" es la razón más valorada por los profesores encuestados, a la hora de optar por este tipo de modalidad de enseñanza (5.05 puntos). En segundo lugar, se sitúa, el "Área temática" (4.63 puntos). Curiosamente, la razón menos valorada por los profesores encuestados es la "Colaboración con otros colegas que impartan la misma asignatura, o cualquier otra" (3.29 puntos), lo que habla de la autonomía e independencia que sigue imperando en el mundo académico, respecto a la forma de impartir docencia.

Por contra, las "Razones de menor satisfacción en asignaturas virtuales", expresadas por los estudiantes, se muestran en la Figura 11. En este caso, no hay ninguna razón que destaque poderosamente frente al resto; la razón más puntuada fue "El curso fue demasiado corto, no permitiendo profundizar en detalle en algunos aspectos" (3.65 puntos), seguida de "El curso no respondió a las expectativas que tenía" (3.45 puntos). 


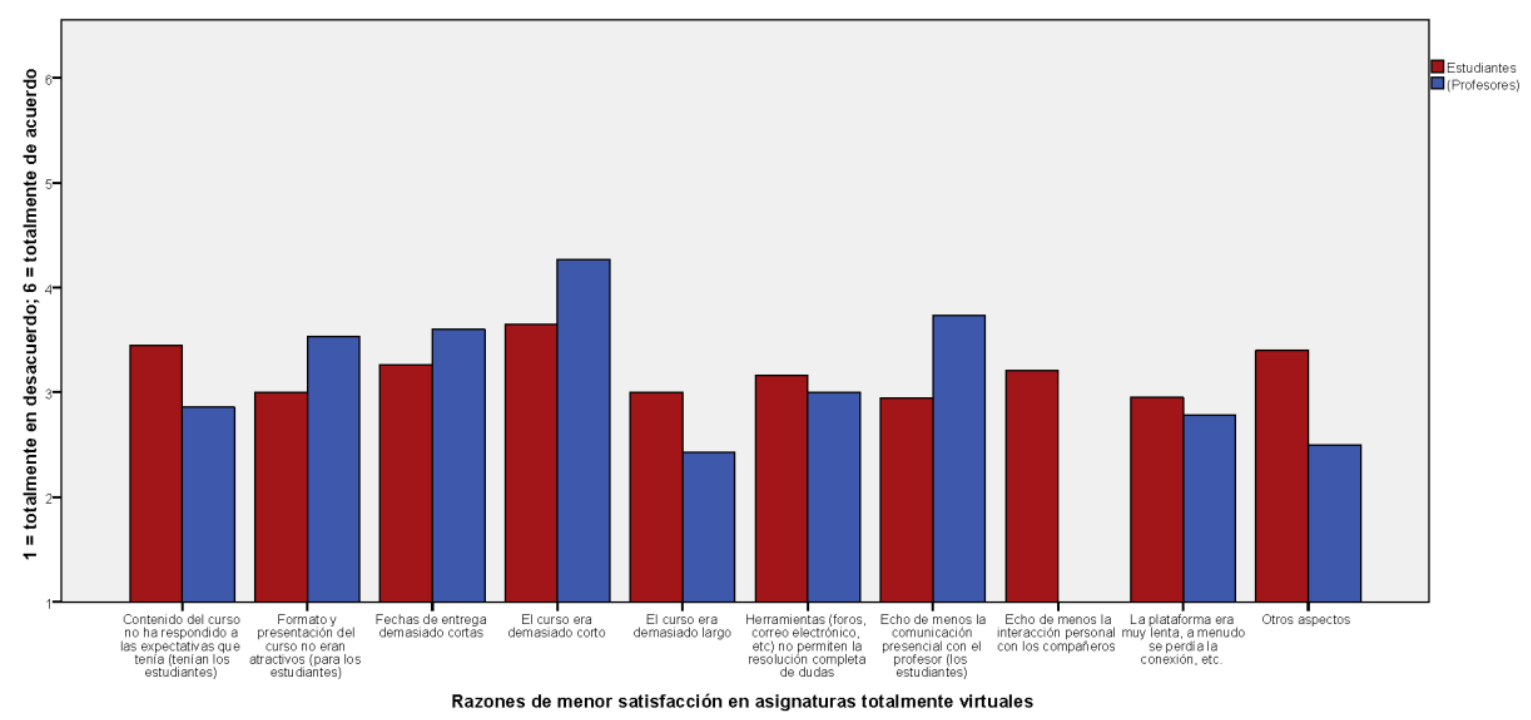

Figura 11. Resultado de la variable VS2.2: Razones de menor satisfacción en asignatura(s) totalmente virtual(es) para estudiantes y profesores

Al igual que en el caso de estudiantes, los profesores han valorado con mayor puntuación que "El curso fue demasiado corto, no permitiendo profundizar en detalle en algunos aspectos" (4.27 puntos, claramente superior al resto de opciones). La siguiente razón más puntuada por los profesores fue "Echo de menos la comunicación real con los estudiantes" (3.73 puntos), lo que vuelve a confirmar la idea de partida de este trabajo, a saber: la plataforma OPTILAB deberá ser un complemento, no una sustitución completa, de la enseñanza de prácticas en el laboratorio real.

A modo de resumen, se ha pregunta a las dos poblaciones que valoren de 1 a 6 el Grado de satisfacción de asignaturas presenciales. La Figura 12 muestra una puntuación promedio de 4.50 puntos para profesores, y 4.26 puntos en el caso de los estudiantes, lo que demuestra que ambos colectivos tienen una buena percepción de la calidad de enseñanza presencial, impartida y recibida en cada caso.

Por su parte, la Figura 13 muestra el Grado de satisfacción de asignaturas virtuales. Los resultados de los estudiantes arrojan una puntuación promedio de 3.12 puntos, sensiblemente inferior a los 4.26 puntos alcanzados por la variable equivalente en enseñanza presencial. En el caso de los profesores, la evaluación promedio fue de 4.33 puntos, superior a la proporcionada por los estudiantes, y no muy lejos de la puntuación alcanzada por la variable equivalente de enseñanza presencial. 


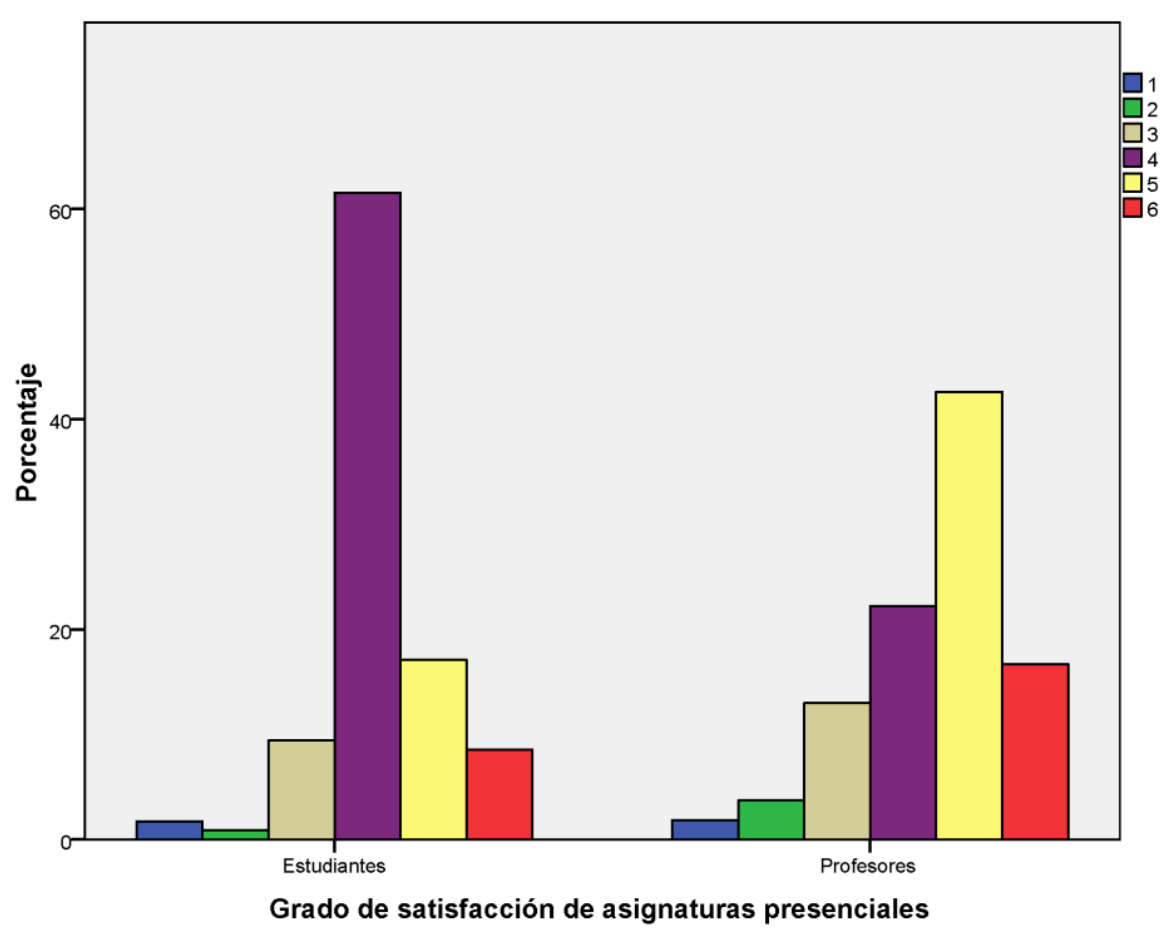

Figura 12. Resultado de la variable VS1.1: Grado de satisfacción de asignaturas presenciales para profesores y estudiantes

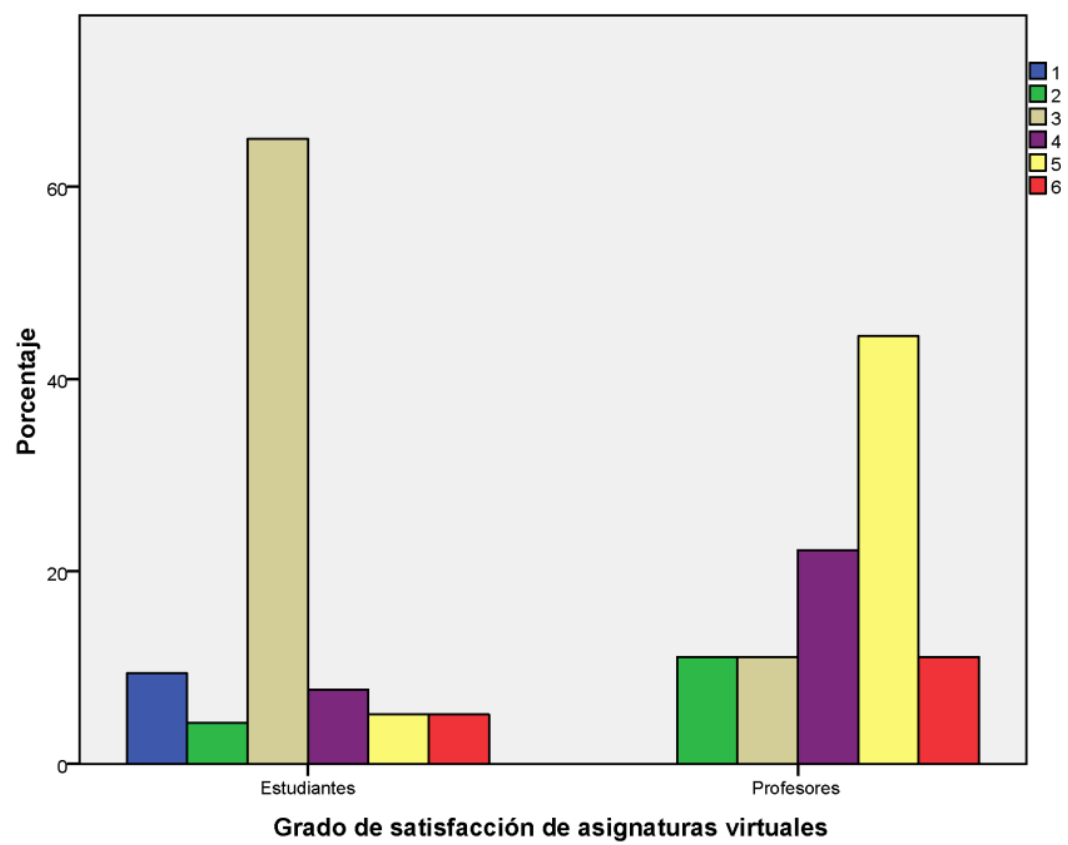

Figura 13. Resultado de la variable VS2.3: Grado de satisfacción de asignaturas virtuales para profesores y estudiantes

En el caso de los profesores, se han añadido una serie de preguntas adicionales, sobre los MOOCs. Como ya se explicó anteriormente, por consejo de los jueces expertos que realizaron la validación del contenido de los cuestionarios, las preguntas específicas sobre MOOC se obviaron en el caso de los estudiantes, pues no hay razón para que un estudiante deba diferenciar entre asignatura virtual reglada y MOOC. Sin embargo, en el caso de los profesores, consideramos que deben estar al tanto de este nuevo paradigma,

Validación de requisitos funcionales de un Laboratorio Virtual Remoto como apoyo al blended learning. J. Gamo et al. 
por lo que se han mantenido estas preguntas, en su formato original.

Como muestra la Figura 14, la mayoría de los profesores no han realizado ningún MOOC como estudiante en los últimos 12 meses (64\%), aunque un 21\% afirma haber cursado al menos un MOOC. Existe un porcentaje en torno al $9 \%$ que no conoce lo que es un MOOC, lo que no es demasiado sorprendente (de hecho, se esperaba tener obtener un porcentaje mayor).

El $79 \%$ de los profesores encuestados declara no haber participado como instructor/coordinador de un MOOC en los últimos 12 meses. Este hecho no es demasiado sorprendente, toda vez que los MOOCs están comenzando a ser conocidos en el ámbito universitario, y todavía hay muchas reticencias a su adopción, como veremos más adelante. No obstante, el $7 \%$ de los encuestados dicen haber participado en, al menos, un MOOC en los últimos 12 meses, como instructor/coordinador.

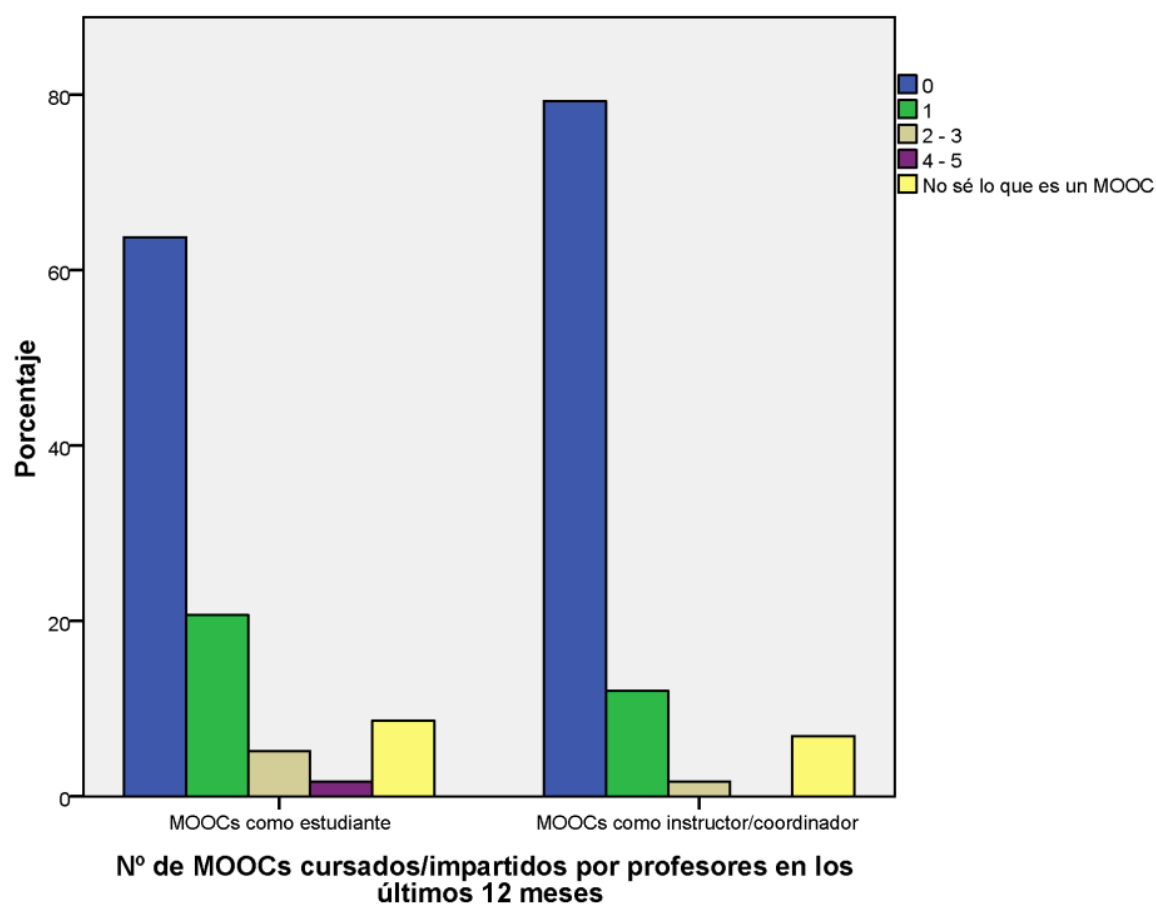

Figura 14. Resultado de las variables PVP3.4: $N^{o}$ de MOOCs como estudiante y PVP3.4: $N^{o}$ de MOOCs como instructor/coordinador

Respecto a las plataformas que alojan los MOOCs donde se declara haber participado como instructores/coordinadores, el 50\% utilizan la plataforma Miriadax, mientras que UNED COMA y el apartado "Otros" se llevaron el 25\% cada uno. Las plataformas más populares para los MOOCs como estudiantes son Miriadax, UNED COMA y Coursera ( $31 \%$ en cada caso).

Las razones que aducen los profesores para no haber participado en ningún MOOC, bien como estudiante, bien como instructor/coordinador, se indican en la Figura 15. Como puede observarse, la razón más frecuente aducida por el profesorado es que no tiene tiempo para cursos en línea, adicionales a las actuales tareas académicas y/o

Validación de requisitos funcionales de un Laboratorio Virtual Remoto como apoyo al blended learning. J. Gamo et al. 
profesionales (4.93 y 4.58 puntos, para cursos como estudiante e instructor, respectivamente). Sin embargo, como segunda opción más valorada, está el hecho de que aún no ha habido oportunidad de cursar/impartir un MOOC, aunque estaría interesado en hacerlo en el futuro (3.74 y 3.88 puntos, respectivamente).

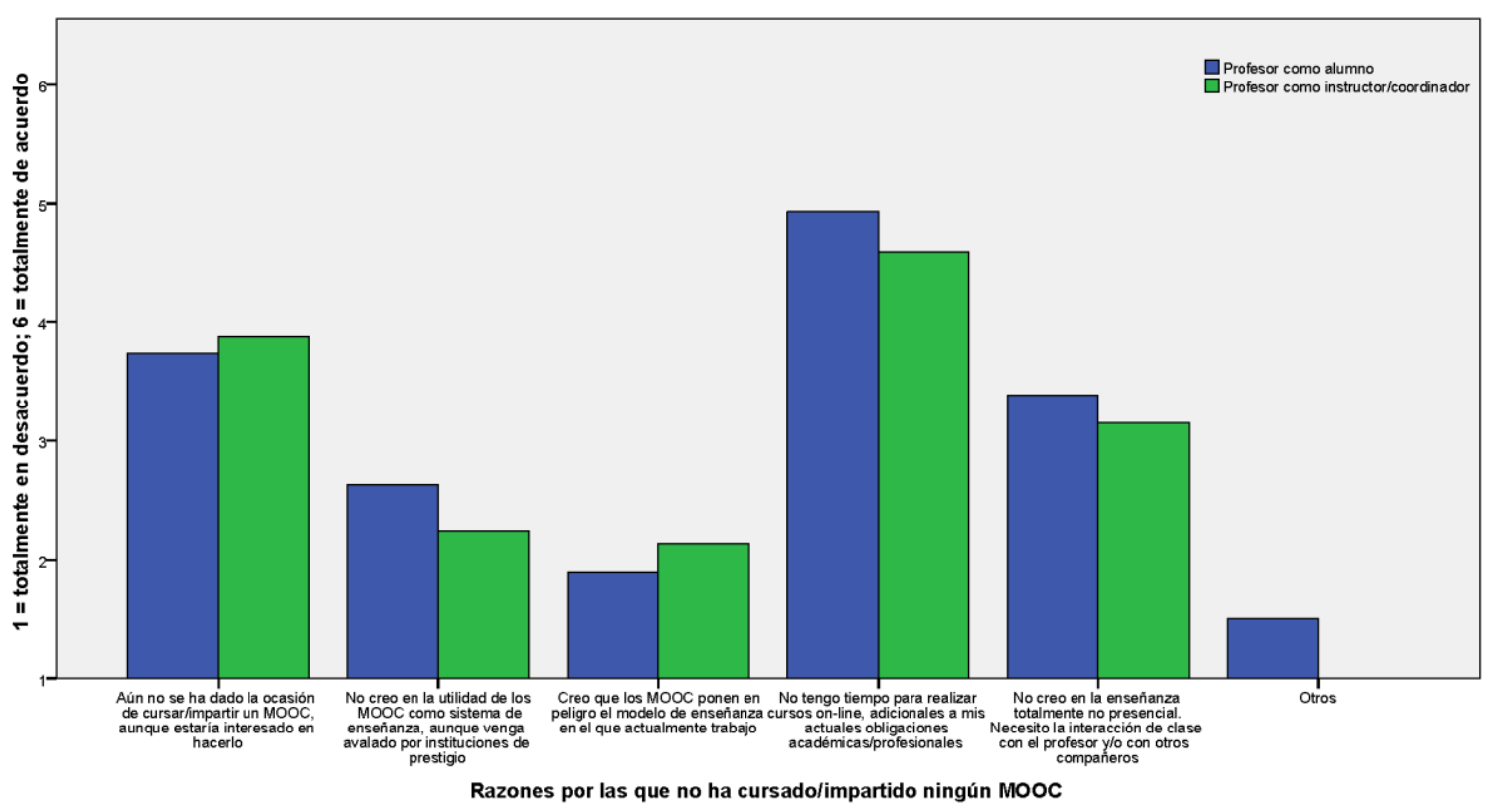

Figura 15. Resultado de las variables PVS3.1a: Razones por las que no ha participado en ningún MOOC como estudiante y PVS3.1b: Ídem como profesor

En el apartado "Otros", se han incluido las siguientes respuestas:

- No soy un estudiante.

Lo cual nos indica que algunos miembros del colectivo de docentes, siguen estableciendo una clara distinción entre profesores y estudiantes.

Como se ha comentado, el bloque de preguntas específicas sobre enseñanza virtual y cultura colaborativa (bloque 3) comienza con la frase: "Piense en una asignatura de las que curse [imparta], que contenga prácticas de laboratorio. Si no tiene ninguna, piense en alguna asignatura/carrera que requiera de algún tipo de práctica experimental". La primera pregunta es: ¿La asignatura en cuestión permite algún tipo de experimentación virtual y/o remota (por ejemplo, simulaciones en línea, gestión remota de instrumentos, etc.)? En el caso de los profesores, predomina la respuesta positiva (61\% "S $S \imath$ " frente al $39 \%$ "No"), lo que representa el caso opuesto frente al de los estudiantes (54\% "No" frente a un $46 \%$ "S $S \imath$ ").

A la pregunta ¿Se debe utilizar una plataforma virtual a distancia, como apoyo a la enseñanza presencial en el laboratorio?, el $77 \%$ de estudiantes y $81 \%$ de profesores encuestados, respondieron afirmativamente. Respecto a las razones por las que sí se deben incluir dicha plataforma VRL, se señalan las respuestas más repetidas de forma conjunta por ambos colectivos:

- Aumenta los medios mediante los cuales los estudiantes aprenden.

- Para preparar las prácticas del laboratorio, afianzar los conocimientos

Validación de requisitos funcionales de un Laboratorio Virtual Remoto como apoyo al blended learning. J. Gamo et al. 
teóricos y reforzar el aprendizaje.

- Es una forma de experiencia paralela al desarrollo de los cursos presenciales, donde no suele dar tiempo a utilizar los recursos del laboratorio. En caso de perder una sesión de laboratorio, la realización de la práctica de forma remota sería muy conveniente.

- Es una buena manera de ser autosuficientes y poder realizar trabajos fuera del centro de enseñanza. Proporciona otra perspectiva.

- Demostración práctica de experimentos en el marco de un entorno seguro. Permite corregir errores practicando con el software desde casa.

- Facilidad y conveniencia. Comodidad para gente que trabaja. En casa se puede ir al ritmo que uno quiera.

- Como apoyo es importante en cuanto a documentación o entrega de prácticas.

- Herramienta muy potente para poner en contacto personas que se encuentran muy alejadas entre sí.

Respecto a las razones para no incluir una plataforma VRL como apoyo al laboratorio presencial, se adujeron las siguientes:

- Siempre el contacto humano es infinitamente mejor al virtual. Tener a alguien competente, y que esté físicamente presente para ayudar a los estudiantes en los procedimientos del laboratorio, es mucho mejor que tener que comunicarse a través de internet.

- Una plataforma virtual viene muy bien para estar al día. Pero en una carrera práctica como una ingeniería, es fundamental la asistencia a un laboratorio, porque es como mejor se aprende. La experiencia real es importante cuando se trata de aprender técnicas de laboratorio

- Porque estoy matriculado en una universidad para ir a clase y deseo tener un profesor dedicado al que pago. Si quisiera una plataforma virtual, me matricularía en una titulación on-line

- Como apoyo no habría ningún problema, pero tarde o temprano, acabaría suplantando el propio laboratorio por motivos económicos.

Respecto a si se ha participado en el diseño, prueba y/o validación de cualquier herramienta digital para la realización de prácticas de laboratorio virtuales y/o remotas, hay un alto porcentaje (49\%) de profesores que dicen haber participado, frente al $16 \%$ únicamente de estudiantes que afirmaba haberlo hecho.

Sobre los contenidos a incluir en la plataforma OPTILAB, como muestra la Figura 16, tanto profesores como estudiantes muestran una clara preferencia hacia las simulaciones software (5.26 puntos para estudiantes; 5.21 puntos para profesores) frente al manejo de instrumentos a distancia (4.86 puntos para estudiantes; 4.52 puntos para profesores). Por tanto, parece que se impone el Laboratorio Virtual frente al Laboratorio Remoto. Los profesores valoran bastante bien los ejercicios de autoevaluación (5.21 puntos) y poner a disposición de los estudiantes del manual de laboratorio (4.87 puntos). Esto último es muy bien valorado también por los estudiantes (5.05 puntos), así como poder descargar vídeos con experimentos reales (5.07 puntos).

Validación de requisitos funcionales de un Laboratorio Virtual Remoto como apoyo al blended learning. J. Gamo et al. 
En el apartado "Otros", se realizaron las siguientes aportaciones:

- Estudiantes: Me parecería importante, si contara para nota, que los estudiantes tuvieran un foro por temas/prácticas/ejercicios/ en el que se pudiera comentar libremente, pero que siempre fuera obligatorio que cada uno expusiera sus propias ideas, por pequeñas que fueran.

- Profesores: Inclusión de herramientas colaborativas.

Ambas opiniones van en la línea de aprendizaje colaborativo en que está inspirado el diseño de la plataforma OPTILAB.

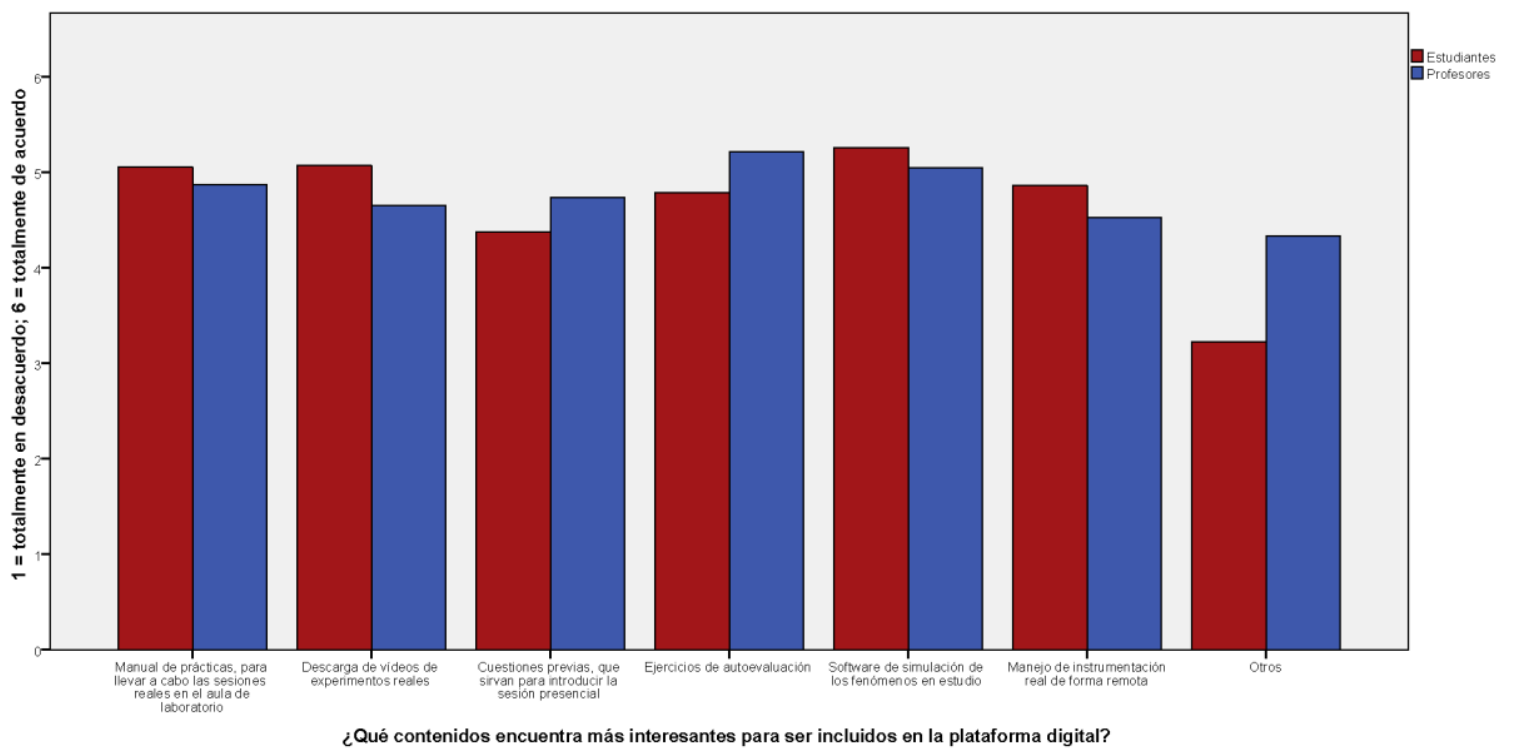

Figura 16. Resultado de la variable VS4.1: ¿Qué contenidos encuentra más interesantes para ser incluidos en la plataforma digital? para estudiantes y profesores

La siguiente variable analizada son las herramientas que considere más útiles de la plataforma virtual. Como puede observarse en la Figura 17, el correo electrónico es la herramienta más valorada por los estudiantes (4.91 puntos), seguida de los foros de discusión abiertos (4.46 puntos). Respecto a los profesores, los enlaces externos para ampliar información (4.78 puntos) y los foros de discusión abiertos (4.73 puntos) son, por este orden, las herramientas mejor valoradas por este colectivo.

En el apartado “Otros", se mencionaron las siguientes herramientas adicionales:

- Estudiantes: Video-tutoriales de explicación.

- Profesores: Ejercicios interactivos. Wikis. Puesta en contacto con estudiantes de otros países

Estos resultados indican que ambos colectivos tienen interés, tanto por herramientas colaborativas, como en las basadas en el aprendizaje autónomo, por lo que ambas deberán coexistir en la futura plataforma OPTILAB. Es de destacar la tercera aportación (contacto con estudiantes de otros países), pues esta iniciativa sirve para el desarrollo, tanto profesional, como personal, del estudiante. Lamentablemente, muchos estudiantes no pueden permitirse viajar a otros países para continuar sus estudios (los programas

Validación de requisitos funcionales de un Laboratorio Virtual Remoto como apoyo al blended learning. J. Gamo et al. 
tipo Erasmus, son escasos en dotación económica, y no siempre llegan a todos los demandantes). En este sentido, el uso adecuado de las TIC a través de una plataforma VRL, puede servir para romper estas barreras geográficas, y poner en contacto a estudiantes de países y ámbitos culturales diferentes.

Respecto al conocimiento y uso de herramientas colaborativas, Dropbox y Google Drive son las herramientas más utilizadas por estudiantes y profesores.

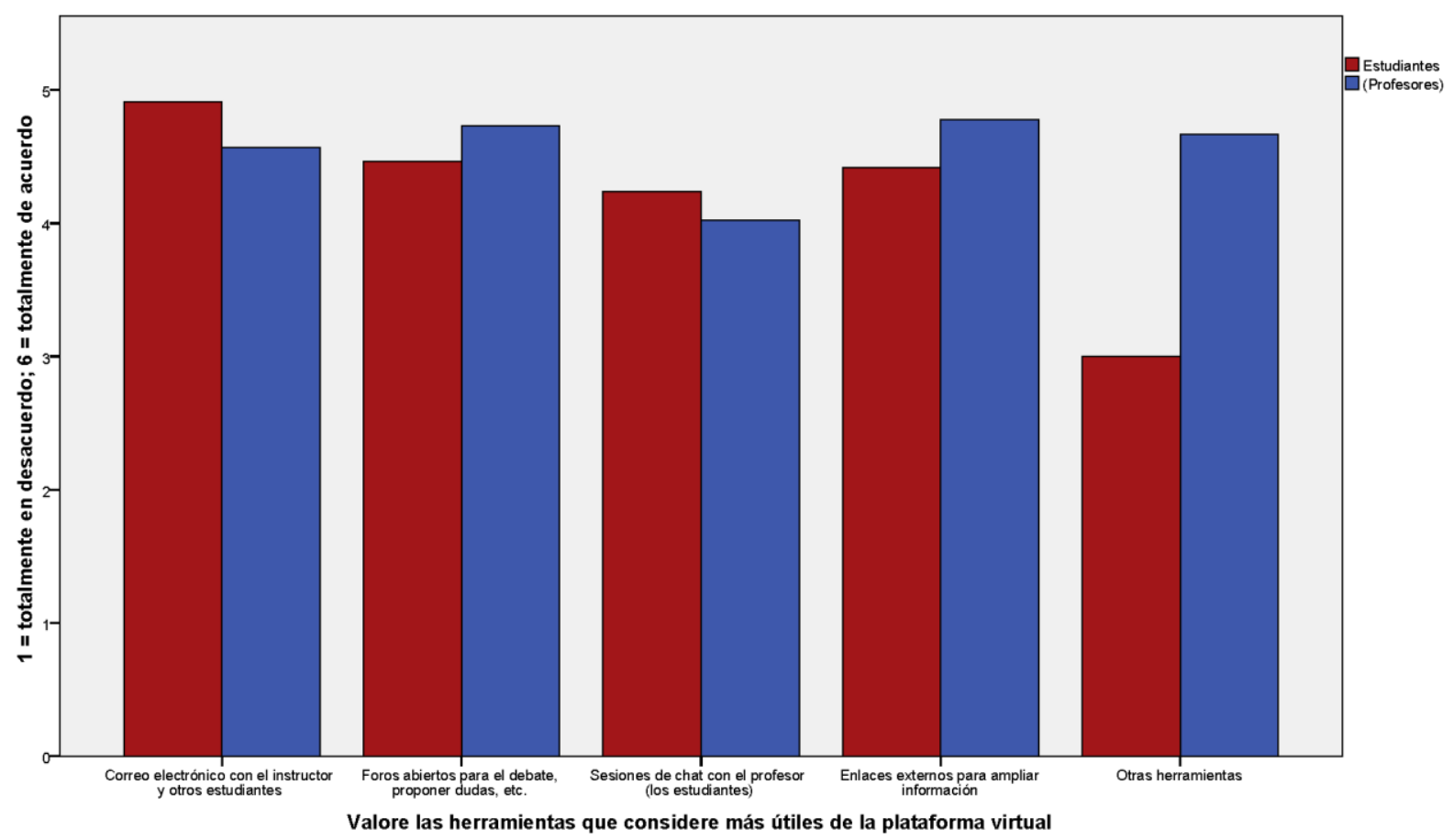

Figura 17. Resultado de la variable VS5.1: Valore las herramientas que considere más útiles de la plataforma virtual para estudiantes y profesores

La presencia en redes sociales del profesorado es inferior, en promedio, a la de los estudiantes. Así, los resultados de la Figura 18 señalan que la red social más utilizada por ambos colectivos es Facebook (4.97 puntos para estudiantes, 3.60 puntos para profesores). No es ninguna sorpresa que los profesores utilicen bastante Linkedin, red social orientada al mundo laboral (3.58 puntos, por 2.74 puntos para estudiantes), frente a redes más lúdicas como Instagram (2.43 puntos, 3.26 puntos para estudiantes). 


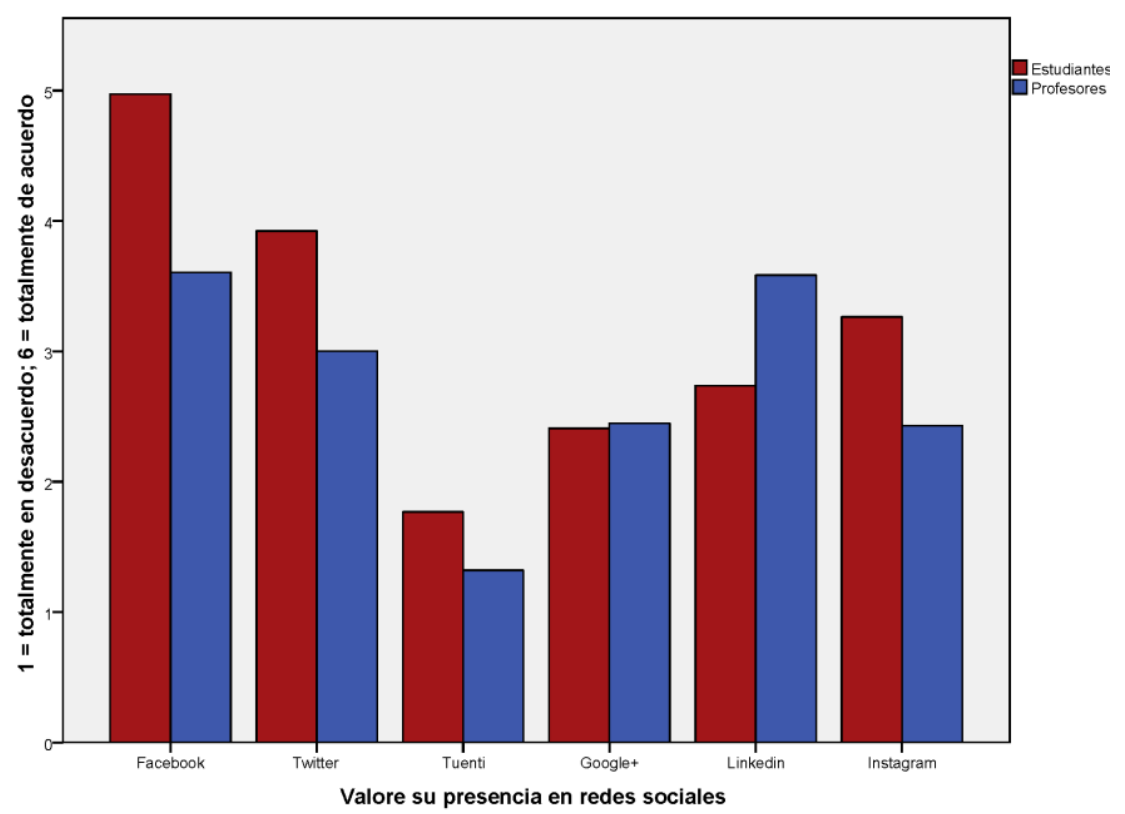

Figura 18. Resultado de la variable PVS6.3: Presencia en redes sociales para estudiantes y profesores

Finalizamos el estudio del cuestionario de requisitos con la pregunta ¿Escribe en algún blog? Únicamente 3 profesores y 5 estudiantes contestaron positivamente. Los blogs mencionados, relacionados con la temática de este trabajo, son los siguientes:

\section{- Estudiantes:}
○ http://www.lavozdelaciencia.com
○ http://martas.me

- Profesores:
○ http://www.lavozdelaciencia.com
○ http://www.eag.com

\section{Conclusiones y líneas futuras}

En este trabajo, se ha realizado una investigación sobre las necesidades y expectativas de profesores y estudiantes, en lo referente al uso de una plataforma de experimentación virtual en enseñanzas científico-técnicas universitarias.

Para tal fin, se han recabado las opiniones de los usuarios (estudiantes y profesores de universidades nacionales y extranjeras), mediante sendos cuestionarios de requisitos, los cuales han sido validados previamente por expertos nacionales e internacionales, en las áreas de didáctica y ciencias/ingeniería.

Una vez cumplimentados los cuestionarios, se ha realizado el análisis de fiabilidad de los datos, mediante el cálculo del coeficiente alfa de Cronbach, el cual ha demostrado que los resultados obtenidos, son fiables en todos los casos.

A continuación, se ha realizado el análisis descriptivo de los datos. A tenor de los 
resultados, la utilización de una plataforma que implemente un VRL, parece tener una buena acogida entre los dos colectivos encuestados, como complemento de la experimentación en el laboratorio tradicional. Las razones para ello son diversas, como han expresado los comentarios recabados: desde la compatibilización con la vida laboral y personal, pasando por la posibilidad de aumentar las formas de aprendizaje.

Sin embargo, hay que notar que existen miembros de ambos colectivos, que aún son reacios a adoptar esta forma de aprendizaje; en muchos casos, los VRL se ven como una amenaza, que sustituirá tarde o temprano a las prácticas experimentales en el laboratorio presencial. De ahí que haya que insistir en la tesis, defendida por los autores, que los VRL deben ser considerados como una herramienta más en el sistema de enseñanza-aprendizaje de las disciplinas científico-técnicas, que en ningún caso puede suplantar la experimentación real en el aula de laboratorio.

El ancho de banda de conexión de que disponen la mayoría de los encuestados, parece ser lo suficientemente grande, como para incluir en la plataforma de VRL aplicaciones y servicios que exijan un importante tráfico de datos, tales como la realización de simulaciones complejas, descarga de vídeo-tutoriales, etc.

Los resultados muestran que ambos colectivos tienen interés, tanto en el aprendizaje autónomo, como en el colaborativo. Parece claro que ambos sistemas de aprendizaje deberán coexistir, por lo que la futura plataforma OPTILAB, incluirá tanto herramientas colaborativas (correo electrónico, foros de discusión, wikis, etc.), como de aprendizaje autónomo (manual de laboratorio, video-tutoriales, enlaces externos, etc.).

En este sentido, cabe destacar varias aportaciones, hechas por profesores y estudiantes, que resaltan el hecho de que el uso adecuado de las TIC en la enseñanza, sirve para poner en contacto a estudiantes de diversos lugares del planeta. En el mundo global en que vivimos, cada vez hay menos barreras, y las plataformas VRL en la enseñanza es un nuevo ejemplo de ello, que incide en los aspectos colaborativo y multicultural del proceso de enseñanza-aprendizaje.

Tanto profesores como estudiantes han mostrado preferencia hacia la simulación de experimentos (Laboratorio Virtual) frente al manejo de instrumentos a distancia (Laboratorio Remoto). Esto refuerza nuevamente la idea de utilizar la plataforma VRL como complemento (no substitución) del laboratorio presencial, de forma que el estudiante pueda ejercitarse en casa, en aquellos experimentos que luego tendrá que realizar físicamente en el aula de laboratorio.

Como líneas futuras de trabajo para completar el desarrollo efectivo de la plataforma OPTILAB, además del aspecto multiplataforma inicialmente contemplado (esto es, independiente del sistema operativo y navegador utilizados), se planteará desde un principio que el diseño de la plataforma VRL sea adecuado también para ser utilizado en entornos móviles (en principio tabletas, aunque no se descartan tampoco los smartphones). Inicialmente, esto no era algo que se había considerado, pero la penetración en el mercado de los dispositivos móviles, cada vez más potentes y ubicuos, hace que deban ser considerados también como una herramienta didáctica más. De esta forma, se espera conseguir un mayor grado de utilización de la plataforma OPTILAB.

Validación de requisitos funcionales de un Laboratorio Virtual Remoto como apoyo al blended learning. J. Gamo et al. 


\section{Agradecimientos}

Los autores desean agradecer a todos los participantes y expertos que contribuyeron en el diseño y cumplimentación de las encuestas.

Fin de redacción del artículo: 18 de febrero de 2015.

Gamo, J. et al. (2015). Validación de requisitos funcionales de un Laboratorio Virtual Remoto como apoyo al blended learning. Revista de Educación a Distancia. 45(1). Consultado el (dd/mm/aaaa) en http://www.um.es/ead/red/45

\section{Bibliografía}

Alberca, M., et al. (2010). El desarrollo de medios materiales y virtuales en el marco de la educación superior a distancia. Madrid: Ramón Areces.

Capmany, J. T. (29 de 09 de 2014). MOOC Fundamentos de Comunicaciones Ópticas. Obtenido de http://cursocomunicacionesopticas.upvx.es/ficha

Carnicer, A. (2014). JOptics Course. Recuperado el 2014, de http://www.ub.edu/javaoptics/

Carreño, F. (2007, 10 25). Teaching Optics Group. Retrieved 04 11, 2014, from http://pendientedemigracion.ucm.es/info/opticaf/OPT_FIS/index.php

Carswell, L. T. (2000). Distance education via the Internet: the student experience. British Journal of Educational Technology, 31(1), 29 - 46.

Chang, G., Yeh, Z., Chang, H., \& Pan, S. (2005). Teaching Photonics Laboratory Using Remote-Control Web Technologies. IEEE Transactions on Education, 48(4), 642651.

Chaos, D., et al. (2013). Virtual and remote robotic laboratory using EJS, Matlab and Labview. Sensors(13), 2595-2612.

Cronbach, L. (1951). Coefficient alpha and the internal structure of tests. Psychometrika, 16, 297 - 334.

Dziabenko, O., \& García-Zubía, J. (2013). IT Innovative Practices in Secondary Schools: Remote Experiments. Bilbao: University of Deusto.

Edmondson, D. R. (2005). Likert scales: a history. En L. C. Neilson (Ed.), The Future of Marketing's Past. Proceedings of the 12th Conference on Historical Analysis and Research in Marketing (CHARM) (págs. 127-133). Long Beach, CA, USA: Association for Historical Research in Marketing.

Validación de requisitos funcionales de un Laboratorio Virtual Remoto como apoyo al blended learning. 
Frey, L. R., \& Botan, C. H. (2000). Investigating comunication. Needham Heights, MA 02494, USA: Allyn and Bacon.

Gamo, J. (2011). A contribution to virtual experimentation in Optics. In I. Naydenova (Ed.), Advanced Holography - Metrology and Imaging (pp. 357-374). Rijeka, Croatia: InTech.

Gamo, J. (4 de noviembre de 2013). Laboratorios virtuales remotos: experimentación a golpe de click. Recuperado el 17 de noviembre de 2014, de http://www.lavozdelaciencia.com/retos-acts/sociedad/laboratorios-virtuales-remotosexperimentacion-a-golpe-de-click.html

Gamo, J. (2014). Survey on Virtual Remote Labs (students). Recuperado el 28 de 10 de 2014, de https://slu.az1.qualtrics.com/SE/?SID=SV_byc1qTRcQfqlq7j

Gamo, J. (2014). Survey on Virtual Remote Labs (teachers). Recuperado el 28 de 10 de 2014, de https://slu.az1.qualtrics.com/SE/?SID=SV_elgxvJqskdgRglT

García-Zubía, J., \& Alves, G. R. (2011). Using remote labs in education. Bilbao, Spain: University of Deusto.

George, D., \& Mallery, P. (1994). SPPS/PC + Step by Step: A Simple Guide and Reference. Belmont, CA,: Wadsworth.

Hardesty, L. (20 de 04 de 2010). Online Labs. Obtenido de MIT Technology Review: http://www.technologyreview.com/article/418515/online-labs/

Infosurv, Inc. (2011). 5-point vs. 6-point Likert Scales. Atlanta, GA: Infosurv .

Likert, R. (1932). A technique for the measurement of attitudes. Archives of Pyschology, 140, 5 - 55.

Mathworks. (2014). MATLAB - The Language Of Technical Computing. Recuperado el 11 de 04 de 2014, de http://www.mathworks.com/products/matlab

Medina, A. (2009). Innovación de la educación y de la docencia. Madrid: Ramón Areces.

MERLOT. (2010). MERLOT Awards: Exemplary Learning Materials. Obtenido de http://documents.merlot.org/Awards/MERLOTAwards_exemplaryClassics.pdf

Mishra, A. (01 de 03 de 2012). Virtual laboratories to reach 500,000 students. Obtenido de University World News, $\mathrm{n}^{\mathrm{o}}$ 211: http://www.universityworldnews.com/article.php?story=20120301115000644

Mitchell-Waldrop, M. (2013). Education online: the virtual lab. Nature, 499(7458), 268 -270 .

Validación de requisitos funcionales de un Laboratorio Virtual Remoto como apoyo al blended learning. 
Nandana, W., de Mel, W., \& Priyankara, H. (2012). Online remote laboratory for open distance learning. First International Conference on Open and Distance e-Learning. Manila, Phillipines.

Ros, S. R.-G. (2012). Using virtualization and automatic evaluation: adapting network services management courses to the EHEA. IEEE Transactions on Education, 55(2), $196-202$.

Snow, J. (18 de 09 de 2014). Qualtrics Survey Software. Handbook for Research Professionals. Obtenido de http://www.qualtrics.com.

Strauss, V. (03 de 10 de 2012). The flip: Turning a classroom upside down. Washington Post.

The Bologna Process. (2014). The European Higher Education Area (EHEA). Obtenido de http://www.ehea.info/

The Bologna Process. (2014). The European Higher Education Area (EHEA). Recuperado el 11 de 04 de 2014, de http://www.ehea.info/

UNED. (2013). Red de Laboratorios Colaborativos Virtuales y Remotos. Obtenido de http://unilabs.dia.uned.es/ 